\title{
Impact of ocean heat transport on the Arctic sea-ice decline: a model study with EC-Earth3
}

\author{
David Docquier $^{1}\left[\right.$ ] Torben Koenigk $^{1} \cdot$ Ramon Fuentes-Franco $^{1} \cdot$ Mehdi Pasha Karami $^{1} \cdot$ Yohan Ruprich-Robert $^{2}$
}

Received: 10 July 2020 / Accepted: 14 November 2020 / Published online: 10 January 2021

(C) The Author(s) 2021

\begin{abstract}
The recent increase in Atlantic and Pacific ocean heat transports has led to a decrease in Arctic sea-ice area and volume. As the respective contributions from both oceans in driving sea-ice loss is still uncertain, our study explores this. We use the EC-Earth3 coupled global climate model and perform different sensitivity experiments to gain insights into the relationships between ocean heat transport and Arctic sea ice. In these model experiments, the sea-surface temperature is artificially increased in different regions of the North Atlantic and North Pacific Oceans and with different levels of warming. All the experiments lead to enhanced ocean heat transport, and consequently to a decrease in Arctic sea-ice area and volume. We show that the wider the domain in which the sea-surface temperature is increased and the larger the level of warming, the larger the increase in ocean heat transport and the stronger the decrease in Arctic sea-ice area and volume. We also find that for a same amount of ocean heat transport increase, the reductions in Arctic sea-ice area and volume are stronger when the sea-surface temperature increase is imposed in the North Pacific, compared to the North Atlantic. This is explained by the lower-salinity water at the Bering Strait and atmospheric warming of the North Atlantic Ocean in the Pacific experiments. Finally, we find that the sea-ice loss is mainly driven by reduced basal growth along the sea-ice edge and enhanced basal melt in the Central Arctic. This confirms that the ocean heat transport is the primary driver of Arctic sea-ice loss in our experiments.
\end{abstract}

Keywords Sea ice $\cdot$ Ocean heat transport $\cdot$ Modeling $\cdot$ EC-Earth

\section{Introduction}

In the current global warming context, Arctic sea ice has dramatically changed over the past decades. Between 1979 and 2018, the sea-ice extent has decreased at a rate of $83,000 \mathrm{~km}^{2} \mathrm{yr}^{-1}$ at the end of summer and $41,000 \mathrm{~km}^{2} \mathrm{yr}^{-1}$ at the end of winter (Meredith et al. 2019). This rate of extent decrease is unprecedented in the record back to 1850 , especially for summer (Walsh et al. 2017). Arctic sea ice has also thinned by $1.5-2 \mathrm{~m}$ since 1980 (Lindsay and Schweiger 2015; Kwok 2018). Concurrently, there has been a shift to younger sea ice, with a decline of $\sim 90 \%$ of the areal proportion of thick ice at least 5 years old between 1979 and 2018 (Meredith et al. 2019). Following the decrease in sea-ice extent and thickness, the Arctic sea-ice volume loss over

David Docquier

docquier.david@gmail.com

1 Swedish Meteorological and Hydrological Institute, Rossby Centre, Norrköping, Sweden

2 Barcelona Supercomputing Center, Barcelona, Spain
1979-2010 is 6 times larger than the decline over 1901-1940 (Schweiger et al. 2019).

The recent Arctic sea-ice changes are strongly driven by anthropogenic global warming via enhanced greenhouse gas concentrations in the atmosphere (Notz and Marotzke 2012; Notz and Stroeve 2016; Meredith et al. 2019), but also by internal variability (Notz and Marotzke 2012; Swart et al. 2015), and are amplified by climate feedbacks (Goosse et al. 2018; Massonnet et al. 2018). Both the anthropogenic global warming and internal variability affect Arctic sea ice through a series of atmospheric (Ding et al. 2017) and oceanic (Carmack et al. 2015 ) processes. Due to its relatively more difficult accessibility, the ocean is probably the least understood cause in Arctic sea-ice changes. An increasing number of studies shows that the heat carried by the Atlantic and Pacific Oceans has a considerable influence on the recent decrease in Arctic sea ice.

The most important gateway through which the ocean heat transport affects sea ice is the Barents Sea Opening (Smedsrud et al. 2010; Muilwijk et al. 2018; van der Linden et al. 2019). Observations show that the recent reduction in winter sea-ice area in the Barents Sea has occurred 
concurrently to an increase in ocean heat transport at the Barents Sea Opening due to both strengthening and warming of the inflow (Arthun et al. 2012). More recently, Polyakov et al. (2017) provide observational evidence that the increased penetration of Atlantic Water into the eastern Eurasian Basin has led to a reduction in sea-ice growth in winter. Although the Bering Strait has a smaller contribution in terms of ocean heat transport to the Arctic compared to the Barents Sea Opening (mean observed value of $14 \mathrm{TW}$ for the Bering Strait and 73 TW for the Barents Sea Opening, Table 1), an increase in heat transport there has also been observed since 1990, mainly due to an increase in the flow (Woodgate 2018), which has influenced the sea-ice retreat in the Chukchi Sea (Serreze et al. 2019). At the Fram Strait, the mean ocean temperature has increased from 1997 to 2010, but there has been no statistical significant trend in the volume transport (Beszczynska-Möller et al. 2012). No significant change in the ocean heat transport through the Davis Strait has been observed between 1987-1990 and 2004-2005 (Curry et al. 2011).

Several modeling studies have confirmed the important role of ocean heat transport in controlling Arctic sea ice. Using 22 climate models from the third phase of the Coupled Model Intercomparison Project (CMIP3), Mahlstein and Knutti (2011) show that the models that simulate a stronger poleward ocean heat transport at $60^{\circ} \mathrm{N}$ also show a smaller September Arctic sea-ice extent. They argue that the northward ocean heat transport largely contributes to the uncertainty in future Arctic climate projections, and that a higher resolution can improve the simulation of climate processes.

Koenigk and Brodeau (2014) show that the Barents Sea Opening dominates the increase in ocean heat transport in their historical and future model simulations with EC-Earth2.3, mainly through increased temperatures. This increased heat transport leads to enhanced heat fluxes at the ice base and contributes to reduced Barents sea-ice area. Results from the NorESM1-M model provide evidence that the increased ocean heat transport at the Barents Sea Opening has a strong influence on the Barents sea-ice area through reduced basal growth, while the sea-ice area reduction in the Central Arctic is mostly controlled by increased ocean heat transport at the Fram Strait via increased bottom melting (Sando et al. 2014).

Combining the results of 32 CMIP5 models shows that the recent decrease in winter Barents sea-ice extent (1979-2015) is strongly connected to the increase in ocean heat transport at the Barents Sea Opening (Li et al. 2017). The CMIP5 ensemble shows an anti-correlation between the annual mean ocean heat flux at $66^{\circ} \mathrm{N}$ and the annual mean Arctic sea-ice area over the period 1961-2099 (historical and RCP4.5 model simulations), although 9 models out of 26 do not show such a negative correlation (Burgard and Notz 2017), which could be partly due to more Arctic regions being ice free in the second half of the 21 st century in these 9 models (Docquier et al. 2019). Lien et al. (2017) find that the impact of ocean heat transport on the Barents sea-ice cover, associated with enhanced local wind, is also present at shorter (monthly) timescales using the Regional Ocean Modeling System (ROMS) combined with different observations.

Muilwijk et al. (2019) use eight different ocean-only models and one fully coupled model and find that a stronger wind forcing over the Greenland Sea leads to an increased ocean heat transport at the Barents Sea Opening and a reduced sea-ice extent in the Barents and Kara Seas. Results from the Community Earth System Model Large Ensemble (CESMLE) show that rapid sea-ice declines are strongly correlated to anomalies in ocean heat transport, mainly at the Barents Sea Opening and Bering Strait (Auclair and Tremblay 2018), and that the ocean heat transport in the Barents Sea is a major source of internal Arctic winter sea-ice variability and predictability (Arthun et al. 2019).

Using five High Resolution Model Intercomparison Project (HighResMIP) models at different horizontal resolutions over the historical period (1950-2014), Docquier et al. (2019) find a robust decline in Arctic sea-ice area with enhanced poleward Atlantic ocean heat transport north of $60^{\circ} \mathrm{N}$. The Barents-Kara and Greenland-Iceland-Norwegian (GIN) Seas are the most affected in terms of sea ice following an increased Atlantic ocean heat transport. A study with two additional HighResMIP models (so 7 models in total with at least two different resolutions) confirms that the changes in the Barents sea-ice area are strongly anti-correlated to the changes in ocean heat transport at the Barents Sea Opening (Docquier et al. 2020). While an increased horizontal resolution allows a better representation of the ocean currents, the strength of the relationship between sea-ice area and ocean heat transport is not affected by resolution.

Due to the smaller ocean heat transport contribution to the Arctic of the three other gateways (Bering, Fram and Davis Straits), a fewer modeling studies have analyzed their impact on Arctic sea ice. Some modeling studies suggest a non-negligible impact of the Bering Strait ocean heat transport on Arctic sea ice. Koenigk and Brodeau (2014) find that the warm water remains near the surface in the shallow Bering Strait, compared to the deeper Barents Sea Opening, in future model projections with EC-Earth2.3, thus potentially contributing to enhanced bottom ice melt. Auclair and Tremblay (2018) also find that the Bering Strait ocean heat transport is highly correlated to rapid ice declines using CESM-LE.

While many studies have analyzed the relationship between ocean heat transport and Arctic sea ice, only a few have investigated the detailed processes by which the ocean heat transport impacts the sea ice. A way to conduct such an 
analysis is by performing model experiments in which the ocean heat transport is varied and by studying the resulting impact on sea ice. This is what we do in this paper, by designing a set of sensitivity experiments in which the seasurface temperature (SST) is artificially enhanced in both the Atlantic and Pacific Oceans. This allows us to study the effect of initially increasing the SST (and thus ocean heat transport) in both oceans on Arctic sea ice.

In Sect. 2, we present the model used, the sensitivity experiments, the observational datasets and the diagnostics. In Sect. 3, we show the main results of our analysis in terms of ocean heat transport, Arctic sea ice and the relationship between the two. In Sect. 4, we discuss the difference of imposing the SST anomalies in the Atlantic or Pacific and the potential role of the atmosphere. We provide our conclusions in Sect. 5.

\section{Methodology}

\subsection{Model experiments}

The model used in this study is version 3.3.1.1 (SVN revision 7299) of the EC-Earth coupled global climate model (Döscher et al. 2020), which is named EC-Earth3 hereafter. This is the version used in the CMIP6 intercomparison. The atmospheric component of the model is cycle $36 \mathrm{r} 4$ of the Integrated Forecast System (IFS) from the European Centre for Medium-Range Weather Forecasts (ECMWF), which includes the H-Tessel land surface model (Balsamo et al. 2009). The ocean component is version 3.6 of the Nucleus for European Modelling of the Ocean (NEMO3.6, Madec 2016), including version 3 of the Louvain-la-Neuve seaIce Model (LIM3, Rousset et al. 2015). The atmosphere/ land and ocean/sea-ice components are coupled through the Ocean, Atmosphere, Sea Ice, Soil (OASIS) coupler (Craig et al. 2017). The atmospheric and ocean grids used in this study are T255 (horizontal resolution of $\sim 80 \mathrm{~km}$ ) and ORCA1 (horizontal resolution of $\sim 1^{\circ}$, with mesh refinement down to $\sim 0.3^{\circ}$ around the equator), respectively. The number of vertical levels is 91 in the atmosphere (model top at $0.01 \mathrm{hPa}$ ) and 75 in the ocean. The model time step is 45 minutes for both the atmosphere and ocean.

Starting from the year 2014 of the rli1p1f1 EC-Earth3Veg historical CMIP6 member (EC-Earth-Consortium 2019), we run 200 years with EC-Earth 3 using constant greenhouse gas and aerosol forcing corresponding to the year 2000. This constitutes our present-day control run, named CTRL hereafter. EC-Earth3-Veg is similar to EC-Earth3 but includes a dynamic vegetation model (LPJ-GUESS v4, Smith et al. 2014). The differences in mean atmospheric and ocean states between the ensemble means of EC-Earth 3 and EC-Earth3-Veg are relatively small (Döscher et al. 2020).
Thus, we are confident that starting our model experiments from either EC-Earth3-Veg or EC-Earth3 does not substantially impact our results.

From the year 117 of the CTRL run, we launch a series of 50 -year long sensitivity experiments with the aim of increasing the poleward ocean heat transport. This specific year is chosen as it provides values of Arctic sea-ice area and volume close to present-day observed values (Fig. 5 and Table 2).

In all the sensitivity experiments, the SST is restored to the mean climatology of the 30 years before the year 117 of the CTRL run, enhanced by $1{ }^{\circ} \mathrm{C}, 3{ }^{\circ} \mathrm{C}$, or $5{ }^{\circ} \mathrm{C}$, in a specific domain of the North Atlantic Ocean or North Pacific Ocean. The restoring is done through the addition of a surface heat flux $q_{s}$ in each grid point:

$q_{s}=c_{T}\left(S S T_{m}-S S T_{t}\right) R$,

where $c_{T}$ is the temperature restoring coefficient (equal to $-40 \mathrm{Wm}^{-2} \mathrm{~K}^{-1}$, based on Servonnat et al. 2015), $S S T_{m}$ is the modeled SST, $S S T_{t}$ is the targeted (restored) SST, and $R$ is the restoring mask ( 1 in the region where the SST is restored; 0 otherwise). This additional surface heat flux leads to an adjustment of the SST in the restoring region. No restoring is performed under sea ice. Outside of the restoring region, the model freely evolves, which allows a full response of the climate system. Further methodological details about the SST restoring can be found in RuprichRobert et al. (2017).

The resulting increase in SST in our model experiments is expected to lead to a direct increase in poleward ocean heat transport (Eq. (2)). The three levels of warming $\left(1{ }^{\circ} \mathrm{C}\right.$, $3{ }^{\circ} \mathrm{C}, 5{ }^{\circ} \mathrm{C}$,) cover a range of potential warming that could potentially occur in the future (Alexander et al. 2018; IPCC 2019). We use one wide, one medium-sized and one small domain for each of the two oceans (Fig. 1). The wide Atlantic domain (ATL1) corresponds to the region between $40^{\circ} \mathrm{N}$ and $80^{\circ} \mathrm{N}$, and between $40^{\circ} \mathrm{W}$ and $20^{\circ} \mathrm{E}$. The ATL1 domain includes the North Atlantic and Norwegian Currents, which drive a substantial amount of heat to the Arctic. The mediumsized Atlantic domain (ATL2) is the northern part of the latter domain, i.e. between $66^{\circ} \mathrm{N}$ and $80^{\circ} \mathrm{N}$, and between $22^{\circ} \mathrm{W}$ and $20^{\circ} \mathrm{E}$. The ATL2 domain is chosen as it is located upstream of the two main Atlantic gateways to the Arctic, i.e. the Barents Sea Opening and Fram Strait. The small Atlantic domain (ATL3) is the region around the Barents Sea Opening (the main Arctic strait in terms of ocean heat transport), i.e. between $70^{\circ} \mathrm{N}$ and $77^{\circ} \mathrm{N}$, and between $15^{\circ} \mathrm{E}$ and $22^{\circ} \mathrm{E}$. The wide Pacific domain (PAC1) corresponds to the region between $30^{\circ} \mathrm{N}$ and $66^{\circ} \mathrm{N}$, and between $120^{\circ} \mathrm{E}$ and $120^{\circ} \mathrm{W}$. The PAC1 region is relatively similar to ATL1 in terms of latitudinal coverage and it extends from the Asian east coasts to the North American west coasts, so that it covers the North Pacific Current and the main water currents 
flowing to the Arctic through the Bering Strait. The mediumsized Pacific domain (PAC2) is the central eastern part of the latter domain, i.e. between $40^{\circ} \mathrm{N}$ and $50^{\circ} \mathrm{N}$, and between $180^{\circ}$ and $120^{\circ} \mathrm{W}$. The PAC2 domain includes part of the Alaskan Current off the west coast of North America, which provides a substantial amount of heat to the Bering Sea. The small Pacific domain (PAC3) is the region around the Bering Strait (the only Arctic strait from the Pacific side), i.e. between $64^{\circ} \mathrm{N}$ and $67^{\circ} \mathrm{N}$, and between $172^{\circ} \mathrm{W}$ and $166^{\circ} \mathrm{W}$. Figure 1 represents the six different domains as black boxes.

Thus, we have a total of 18 sensitivity experiments, with six different domains and three different levels of warming. In our result section (Sect. 3), we focus on the $6 \mathrm{SST}+3{ }^{\circ} \mathrm{C}$ experiments in order to highlight the key results of our analysis. Our main results hold for the other levels of warming. Figures 3, 9 and 16 present the results from all 18 experiments as there is only one data point per experiment for these two figures. The different domains allow to test the influence of imposing the SST anomalies in either the Atlantic or the Pacific Ocean as the heat transport from these two oceans has an impact on Arctic sea ice. They also make it possible to check the impact of a very small restoring region (Barents Sea Opening or Bering Strait) against larger domains.

\subsection{Observations}

In order to evaluate the model results of our CTRL run, different observational products are used for Arctic sea-ice area and volume, ocean heat transport at the Arctic straits and Atlantic Meridional Overturning Circulation (AMOC). The observed sea-ice area is derived using the second version of the global sea-ice concentration climate data record from the European Organisation for the Exploitation of Meteorological Satellites (EUMETSAT) Ocean Sea Ice Satellite Application Facility (OSI SAF; Lavergne et al. 2019), named OSI-450. The spatial resolution of OSI-450 is $25 \mathrm{~km}$. This dataset compares well with independent estimates of sea-ice concentration both in regions with very high sea-ice concentration (3.5-4\% accuracy) and in regions with very low seaice concentration (1.5-2\% accuracy) (Lavergne et al. 2019).

For sea-ice volume, we use the Pan-Arctic Ice-Ocean Modeling and Assimilation System (PIOMAS) reanalysis data (Zhang and Rothrock 2003). PIOMAS is a coupled ocean and sea-ice model with capability of assimilating daily sea-ice concentration and SST. The model is driven by National Centers for Environmental Prediction / National Center for Atmospheric Research (NCEP/NCAR) reanalysis surface forcing fields. The mean horizontal resolution in the Arctic is $22 \mathrm{~km}$. PIOMAS sea-ice thickness data agree well with satellite altimetry over the Central Arctic with a mean difference lower than $0.1 \mathrm{~m}$ (Schweiger et al. 2011).

For the ocean heat transport at the Barents Sea Opening, we use the mean over the 1997-2007 period based on observations from Smedsrud et al. (2010), considering the section between northern Norway and Bear Island. This section includes the inflows from the Atlantic Water (middle) and Norwegian Coastal Current (south) and outflow from the Bear Island Trench (north). For the ocean heat transport at the Fram Strait, we use the mean over the 1997-2009 period based on observations from Schauer and BeszczynksaMöller (2009). For the ocean heat transport at the Bering Strait, we use the mean over 2000-2015 from the observations of Woodgate (2018). And finally, for Davis Strait, we use the mean observed ocean heat transport over 2004-2005 from Curry et al. (2011).

For the AMOC observations, we make use of the mean over 2005-2017 coming from the RAPID array (Smeed et al. 2019), an observing system deployed at $26.5^{\circ} \mathrm{N}$.

\subsection{Diagnostics}

In our study, we compute a series of diagnostics to investigate the role of ocean heat transport on Arctic sea ice. We compute the poleward ocean heat transport at four different Arctic straits: the Barents Sea Opening, Fram Strait, Bering Strait and Davis Strait, which allows to close the Arctic domain. The coordinates of the transects we use are provided in Table 1 and the four straits are indicated in Fig. 1a using arrows for the direction of the ocean heat transport. We compute the total Arctic Ocean heat transport as the sum of the ocean heat transports through the four straits (Table 1, Figs. 2 and 9). The Atlantic Ocean heat transport is the sum of the heat transports at the Barents Sea Opening and Fram Strait (Fig. 16a).

The ocean heat transport $O H T$ at each strait is computed on the native NEMO grid as:

$O H T=\rho c_{p} \int_{A} \mathbf{U}\left(T-T_{\text {ref }}\right) d A$,

where $\rho$ is the water density $\left(1027 \mathrm{~kg} \mathrm{~m}^{-3}\right), c_{p}$ is the specific seawater heat capacity $\left(3985 \mathrm{~J} \mathrm{~kg}^{-1} \mathrm{~K}^{-1}\right), A$ is the surface area of the section, $\mathbf{U}$ is the ocean velocity perpendicular to the section, $T$ is the ocean potential temperature, and $T_{\text {ref }}$ is the reference temperature (set to $0{ }^{\circ} \mathrm{C}$ ). For each strait, we follow the shortest broken line connecting the two relevant points, which coordinates are provided in Table 1. Both zonal and meridional components of ocean velocity $\mathbf{U}$ are used in this computation. The ocean heat transport is vertically integrated over the whole water column and horizontally integrated over the length of the transect.

In order to understand the origin of changes in ocean heat transport, we decompose this quantity into changes coming from temperature, changes coming from velocity and their covariance, following the same methodology as van der Linden et al. (2019) (Fig. 3). We also compute the horizontal ocean heat flux integrated over the vertical column (norm 
of meridional and zonal components) for each grid point of the model domain to analyze the spatial distribution of ocean heat transport (Fig. 4). All our computations of ocean heat transport and flux use monthly mean values of $\mathbf{U}$ and $T$.

In our study, we focus on the relationships between ocean heat transport and Arctic sea ice. A detailed analysis of atmospheric fields goes beyond the scope of our study, but we acknowledge that our experiments also affect the atmosphere, so we also consider the atmospheric response. In Sect. 4, we have included a discussion on the role of the atmosphere on the ocean heat transport in our experiments. In Fig. 14, we provide latitudinal transects of poleward ocean and atmosphere heat transports. The ocean heat transport represented in this figure is the total heat transport from all ocean basins directed towards the north and is computed online during the model simulations using the meridional velocity and potential temperature of the ocean. The total heat transport is computed offline by integrating the net incoming radiation at the top of the atmosphere from the south to the north (assuming that the system is at equilibrium). The atmospheric heat transport is also computed offline as the integration of the difference between the net incoming radiation at the top of the atmosphere and the net incoming surface heat fluxes from the south to the north.

In Fig. 15, the net atmospheric surface heat flux is the sum of net shortwave and longwave radiations, latent and sensible heat fluxes, all positive towards the surface. The mean Atlantic and Pacific surface heat fluxes (Fig. 16) are the net atmospheric surface heat fluxes integrated over the North Atlantic Ocean $\left(50-80^{\circ} \mathrm{N}, 40^{\circ} \mathrm{W}-20^{\circ} \mathrm{E}\right)$ and North Pacific Ocean $\left(45-66^{\circ} \mathrm{N}, 150^{\circ} \mathrm{W}-150^{\circ} \mathrm{E}\right)$, respectively. These two specific regions are chosen such that they cover the same ocean area, i.e. $\sim 7$ million $\mathrm{km}^{2}$, and are bounded at the north by the Barents Sea Opening and Fram Strait for the North Atlantic region and by the Bering Strait for the North Pacific region (see Fig. 15 for the precise location of these regions). For the Atlantic region, this box is where most changes in net atmospheric surface heat flux occur (Fig. 15e-g).

The Arctic sea-ice area is the product of sea-ice concentration and grid-cell area, summed over all grid cells north of $40^{\circ} \mathrm{N}$ (Figs. 5, 6a, b and 9a-b). The Arctic sea-ice volume is computed in a similar way as sea-ice area but with the equivalent sea-ice thickness instead of sea-ice concentration (Figs. 6c-d and 9c, d). The remaining diagnostics analyzed here are direct outputs of the model: SST (Fig. 1), sea-ice concentration (Fig. 7), equivalent sea-ice thickness (or seaice volume per area, Fig. 8), ocean potential temperature (Fig. 10) and sea-ice mass balance terms (Figs. 11-13).

In the following, we compare the results of our sensitivity experiments, in which the SST is artificially increased, to the CTRL run over the 50-year reference period. As previously explained, we focus on the SST $+3{ }^{\circ} \mathrm{C}$ experiments, but our results hold for the two other levels of warming.

\section{Results}

\subsection{Sea-surface temperature (SST) and ocean heat transport}

The mean SST in the North Atlantic and North Pacific Oceans increases in all sensitivity experiments compared to the CTRL run (Fig. 1), and the SST increase is larger
Table 1 Mean ocean heat transport (in TW $\left[=10^{12} \mathrm{~W}\right]$ ) for the total Arctic (all straits) and the different straits (Barents Sea Opening [BSO], Bering Strait, Fram Strait, Davis Strait), averaged over 50 years, for the CTRL run and the $6 \mathrm{SST}+3^{\circ} \mathrm{C}$ sensitivity experiments

\begin{tabular}{llllll}
\hline Experiment & $\begin{array}{l}\text { Total Arctic } \\
(4 \text { straits })\end{array}$ & $\begin{array}{l}\text { BSO } \\
20^{\circ} \mathrm{E}\end{array}$ & $\begin{array}{l}\text { Bering } \\
65.7^{\circ} \mathrm{N}\end{array}$ & $\begin{array}{l}\text { Fram } \\
79^{\circ} \mathrm{N}\end{array}$ & $\begin{array}{l}\text { Davis } \\
69^{\circ} \mathrm{N}\end{array}$ \\
& & $70-77^{\circ} \mathrm{N}$ & $170.5-168^{\circ} \mathrm{W}$ & $20^{\circ} \mathrm{W}-11^{\circ} \mathrm{E}$ & $67-51^{\circ} \mathrm{W}$ \\
\hline $\mathrm{CTRL}$ & $118.4 \pm 13.1$ & $90.2 \pm 17.0$ & $18.0 \pm 5.0$ & $7.1 \pm 9.8$ & $3.1 \pm 1.2$ \\
Observations & 143 & 73 & $14 \pm 5$ & $36 \pm 6$ & $20 \pm 9$ \\
ATL1 $+3^{\circ} \mathrm{C}$ & $212.8 \pm 24.1$ & $176.8 \pm 27.9$ & $20.4 \pm 6.9$ & $12.9 \pm 23.6$ & $2.6 \pm 2.9$ \\
$\mathrm{ATL} 2+3^{\circ} \mathrm{C}$ & $155.0 \pm 13.1$ & $113.6 \pm 15.3$ & $20.4 \pm 5.6$ & $18.1 \pm 8.8$ & $3.0 \pm 1.4$ \\
$\mathrm{ATL} 3+3^{\circ} \mathrm{C}$ & $137.0 \pm 15.9$ & $102.6 \pm 22.0$ & $22.6 \pm 6.3$ & $7.9 \pm 14.0$ & $4.0 \pm 1.7$ \\
PAC $1+3^{\circ} \mathrm{C}$ & $176.7 \pm 15.9$ & $129.2 \pm 19.6$ & $30.6 \pm 6.7$ & $14.8 \pm 9.3$ & $2.1 \pm 3.3$ \\
PAC2 $+3^{\circ} \mathrm{C}$ & $134.3 \pm 16.8$ & $101.4 \pm 24.1$ & $19.7 \pm 6.0$ & $10.2 \pm 13.7$ & $2.9 \pm 1.7$ \\
PAC3 $+3^{\circ} \mathrm{C}$ & $143.1 \pm 18.6$ & $110.2 \pm 14.8$ & $25.5 \pm 6.4$ & $3.9 \pm 9.4$ & $3.5 \pm 0.9$ \\
\hline
\end{tabular}

The number after the \pm sign is the standard deviation of the annual mean ocean heat transport, which represents the interannual variability over the 50 years. If the difference between the sensitivity experiment and the CTRL run is not significant (5\% level), the ocean heat transport is indicated in italic. We also provide observational estimates for the BSO (mean over 1997-2007, Smedsrud et al. 2010), Bering Strait (mean over 2000-2015, Woodgate 2018), Fram Strait (mean over 1997-2009, Schauer and BeszczynksaMöller 2009), Davis Strait (mean over 2004-2005, Curry et al. 2011), and the total Arctic (sum of the four contributions). The coordinates of the 4 transects used to compute the ocean heat transport are provided below the strait names 
with a higher level of warming (not shown). The SST averaged over 50 years increases by $1-3{ }^{\circ} \mathrm{C}$ in the region where the SST is restored (defined as a black box in each panel of Fig. 1), compared to the CTRL run.
Outside of the restoring region, the SST also increases, but with contrasting differences between the experiments. The SST increase is especially widespread in the wide domain experiments, i.e. ATL $1+3{ }^{\circ} \mathrm{C}$ and PAC $1+3{ }^{\circ} \mathrm{C}$
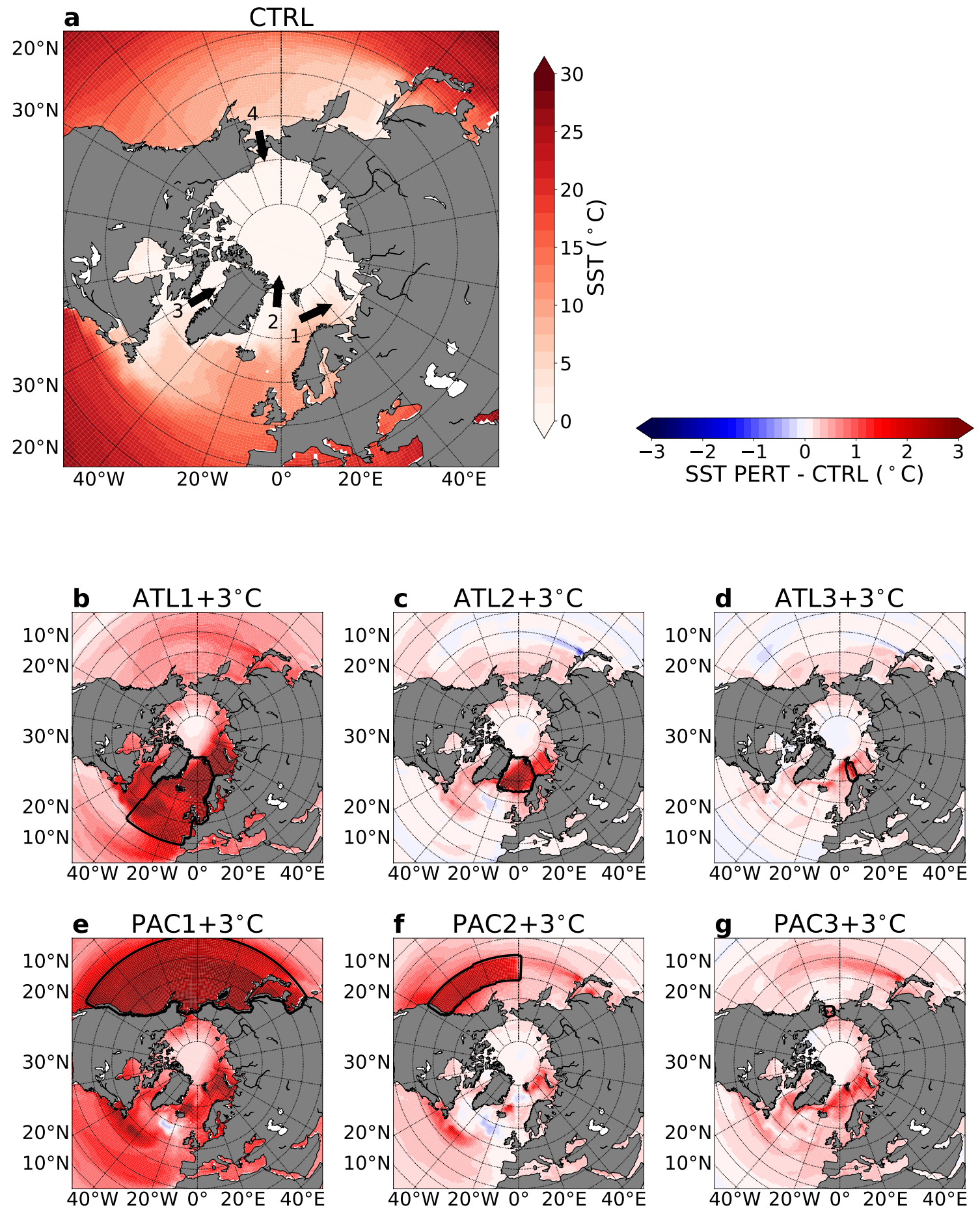

Fig. 1 a Map of mean sea-surface temperature (SST, 50-year average) for the CTRL run, with indication of the main ocean heat transport gateways to the Arctic (1: Barents Sea Opening; 2: Fram Strait; 3: Davis Strait; 4: Bering Strait). b-g Maps of difference in mean SST (50-year average) between the Atlantic (middle row) / Pacific (bottom row) $\mathrm{SST}+3{ }^{\circ} \mathrm{C}$ experiments (PERT) and the CTRL run. The domain in which the SST restoring is applied is shown as a black box for each experiment 
(Fig. 1b, e). In the medium-sized domain experiments (Fig. 1c, f), the SST increase is more confined to the region directly around the restoring domain, with an additional pronounced increase in the Barents and Iceland Seas and in the vicinity of the Gulf Stream / North Atlantic Current at $\sim 40^{\circ} \mathrm{N}$ in PAC $2+3{ }^{\circ} \mathrm{C}$ (Fig. 1f). The SST increase is much more concentrated in the small domain experiments (Fig. 1d,g), although the SST substantially increases (by $>1{ }^{\circ} \mathrm{C}$ ) in the $\mathrm{GIN}$ and Barents Seas in PAC $3+3^{\circ} \mathrm{C}$ (Fig. 1g). Interestingly, all Pacific experiments show a pronounced SST increase in the North Atlantic Ocean (Fig. 1e-g), while the SST increase in the North Pacific Ocean is less intense in the Atlantic experiments (Fig. 1b-d).

The mean total Arctic Ocean heat transport in the CTRL run, summing the contributions from the Barents Sea Opening, Bering, Fram and Davis Straits, is lower by $21 \%$ compared to the observational estimate (Table 1). This is driven by a model underestimation of the ocean heat transport at the Fram Strait and Davis Strait, which is partly compensated by a model overestimation of the transport at the Barents Sea Opening and Bering Strait. However, observational estimates of ocean heat transport contain a relatively large uncertainty and are mean values averaged over different time periods, so the comparison between these observations and our CTRL run must be made with caution. Furthermore, the ocean heat transport at Davis Strait is likely to be a maximum value (Curry et al. 2011), so the model overestimation may be lower.

Following the increase in SST, the total ocean heat transport through all Arctic straits (Barents Sea Opening, Bering, Fram and Davis Straits) increases relative to the CTRL run (Fig. 2 and Table 1) and remains relatively stable over the entire length of the model simulations (Fig. 2. The interannual variability of the total Arctic Ocean heat transport (defined as one standard deviation around the mean) is $~$ $10 \%$ of the mean (Table 1 ).

The increase in total Arctic Ocean heat transport is especially strong in the wide domain experiments, with

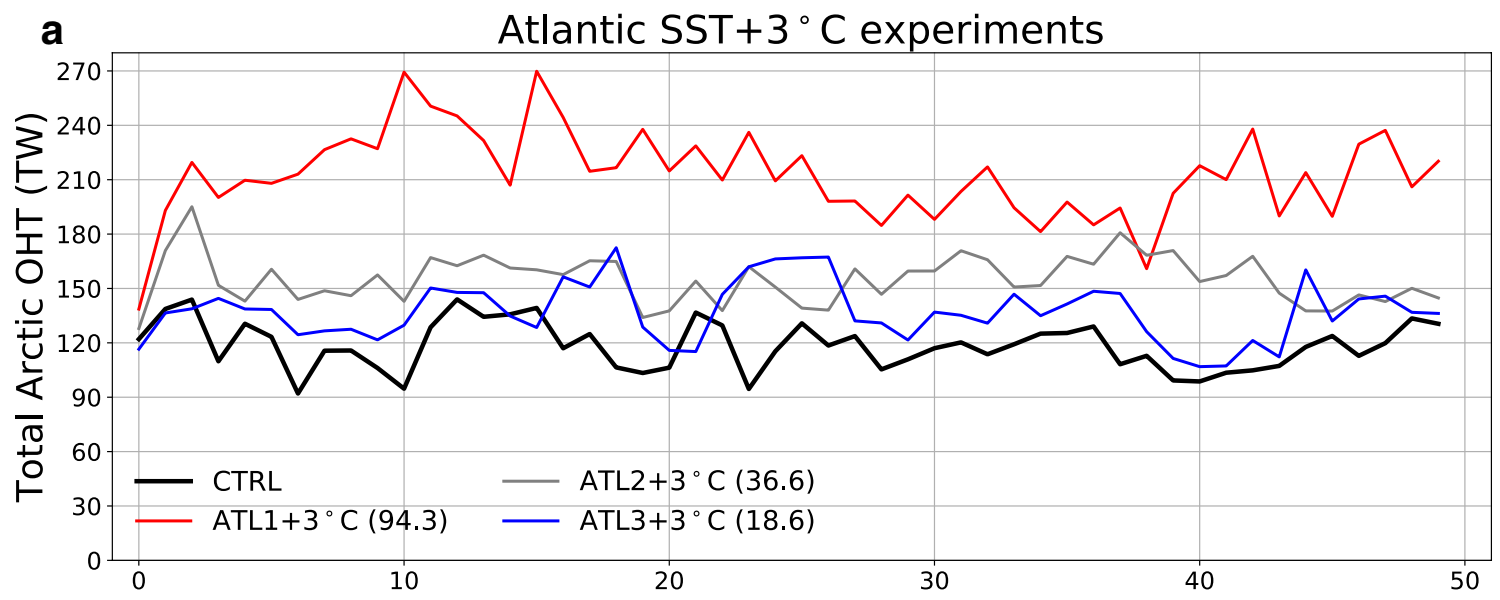

b

Pacific SST $+3^{\circ} \mathrm{C}$ experiments

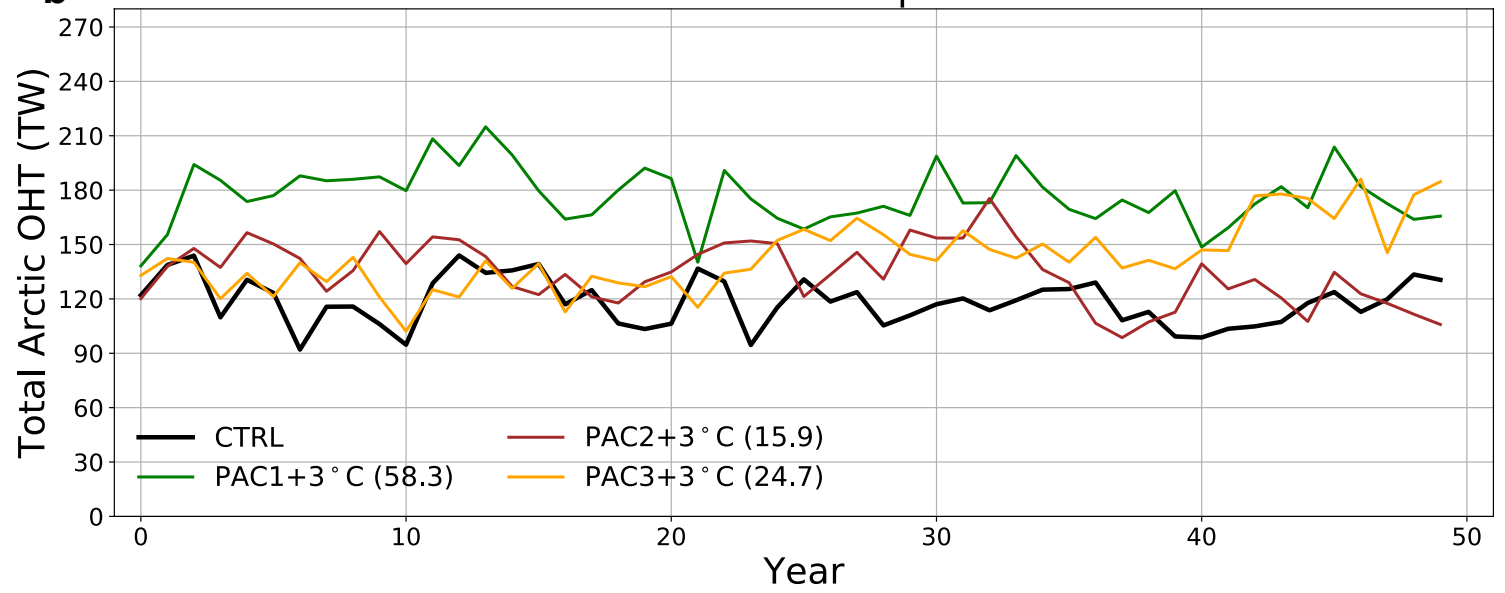

Fig. 2 Time series of ocean heat transport (OHT) through all Arctic straits for the CTRL run, (a) the 3 Atlantic and (b) the 3 Pacific $\mathrm{SST}+3^{\circ} \mathrm{C}$ experiments. The number in brackets in the legend is the difference in mean OHT between the experiment and the CTRL. Year 0 corresponds to the year from which the sensitivity experiments are started 
an increase of $80 \%$ in ATL $1+3{ }^{\circ} \mathrm{C}$ (Fig. 2a) and $49 \%$ in PAC $1+3{ }^{\circ} \mathrm{C}$ (Fig. 2b) relative to the CTRL run. The total Arctic Ocean heat transport also increases in the mediumsized and small domain experiments, but with lower intensity (+13 to $+31 \%$, Fig. 2). It is particularly interesting to note that the ocean heat transport increases more in the small domain PAC $3+3{ }^{\circ} \mathrm{C}$ experiment compared to the medium-sized domain PAC $2+3{ }^{\circ} \mathrm{C}$ experiment (Fig. 2b). As the $\mathrm{PAC} 3$ restoring domain is much smaller than PAC2, we expect a lower effect of the restoring on the PAC3 experiments. However, the difference in ocean heat transport between PAC $3+3{ }^{\circ} \mathrm{C}$ and $\mathrm{PAC} 2+3{ }^{\circ} \mathrm{C}$ is relatively small (8.8 TW, Table 1 ) and not significant at the $1 \%$ level, while other inter-experiment differences are significant with the same $1 \%$ level. Also, the PAC2 domain does not include the area just south of the Bering Strait and there is probably a non-negligible amount of re-circulation towards the south with the PAC2 domain. This can also partly explain the smaller ocean heat transport in the $\mathrm{PAC} 2+3{ }^{\circ} \mathrm{C}$ experiment compared to $\mathrm{PAC} 3+3{ }^{\circ} \mathrm{C}$. Finally, we think that part of the relatively large ocean heat transport of $\mathrm{PAC} 3+3{ }^{\circ} \mathrm{C}$ is due to internal variability. An additional experiment similar to $\mathrm{PAC} 3+3{ }^{\circ} \mathrm{C}$, starting from a different year of the CTRL run, shows a smaller change in ocean heat transport compared to the original experiment (not shown), and thus confirms the potential effect of internal variability on $\mathrm{PAC} 3+3{ }^{\circ} \mathrm{C}$. The fact that $\mathrm{PAC} 2+1{ }^{\circ} \mathrm{C}$ and $\mathrm{PAC} 2+5^{\circ} \mathrm{C}$ have a larger ocean heat transport increase than $\mathrm{PAC} 3+1{ }^{\circ} \mathrm{C}$ and $\mathrm{PAC} 3+5^{\circ} \mathrm{C}$, respectively (Fig. 3a), also indicates that internal variability plays a role for $\mathrm{PAC} 3+3{ }^{\circ} \mathrm{C}$.

In the Atlantic experiments, the increase in total Arctic Ocean heat transport is mainly driven by the increase in ocean heat transport at the Barents Sea Opening, followed by a smaller contribution from the Fram Strait for the wide and medium-sized domain experiments (Table 1). In the Pacific experiments, the increase in total Arctic Ocean heat transport is driven by both the increase in ocean heat transport at the Bering Strait and Barents Sea Opening (Table 1). In the wide and medium-sized Pacific experiments, the Fram Strait also plays a non-negligible role in the ocean heat transport increase. It is particularly interesting to have an increase in ocean heat transport at the Barents Sea Opening in the Pacific experiments, and an increase in this quantity at the Fram Strait in the PAC1 and PAC2 experiments. We show later that this is related to an Atlantic Ocean surface warming through the advection of heat from the Pacific by
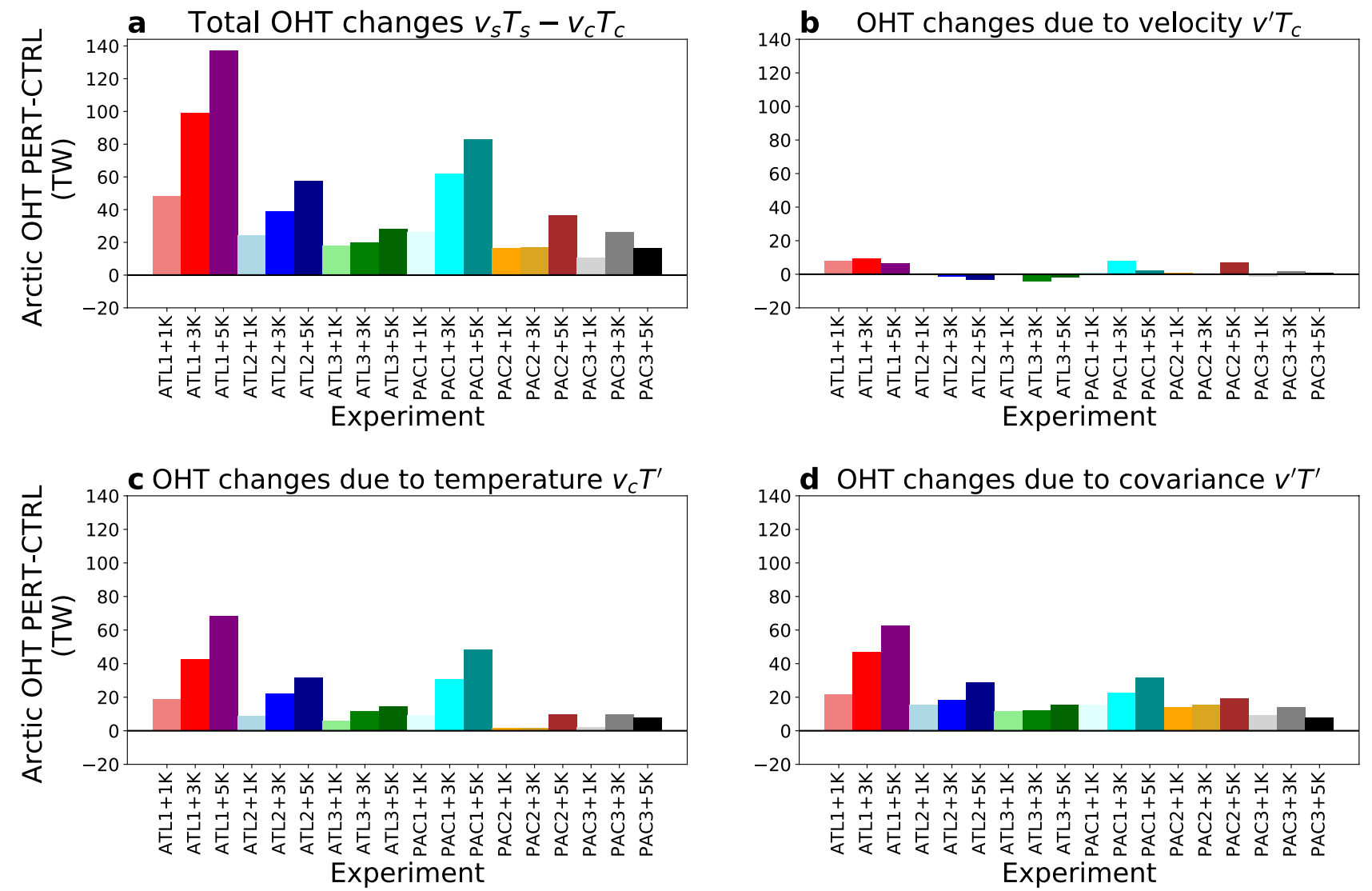

Fig. 3 Mean changes in ocean heat transport (OHT) through all Arctic straits between the sensitivity experiments (PERT) and the CTRL run: (a) total changes, (b) changes due to velocity, (c) changes due to temperature, (d) velocity-temperature covariance 


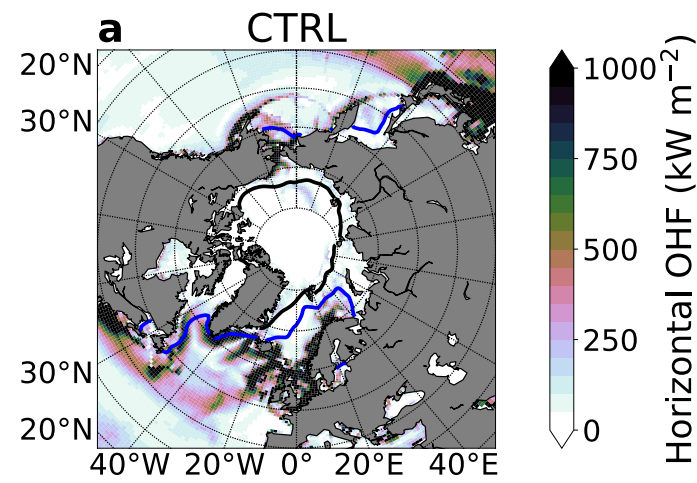

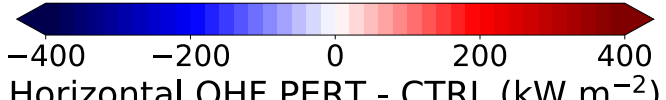

Horizontal OHF PERT - CTRL $\left(\mathrm{kW} \mathrm{m}^{-2}\right)$
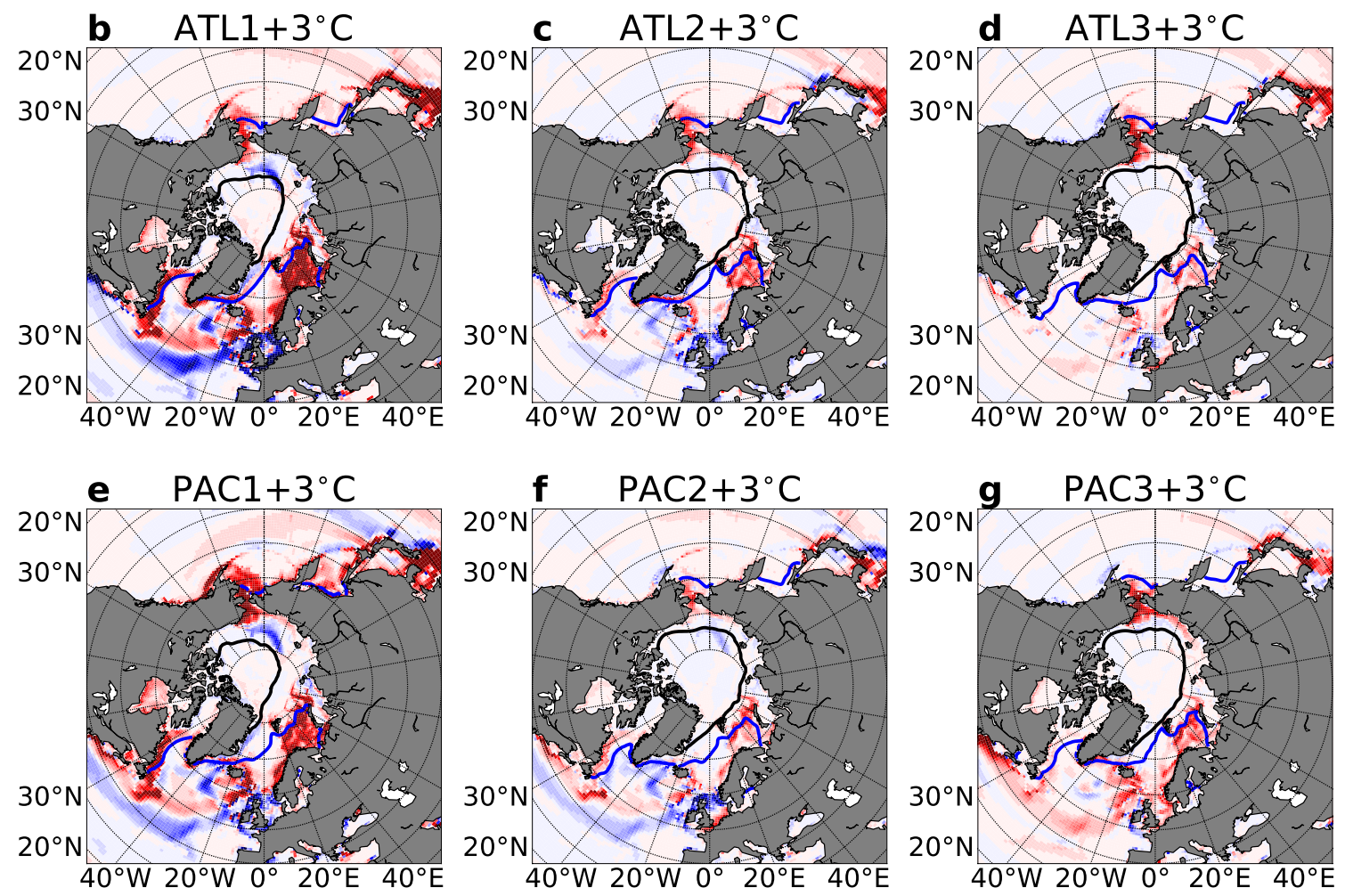

Fig. 4 a Map of mean horizontal ocean heat flux (OHF, 50-year average) for the CTRL run. b-g Maps of difference in mean OHF (50year average) between the Atlantic (middle row) / Pacific (bottom row) $\mathrm{SST}+3^{\circ} \mathrm{C}$ experiments (PERT) and the CTRL run. The blue and black contour lines show the mean March and September sea-ice edges ( $15 \%$ concentration), respectively, of the different experiments the atmosphere. We further investigate this mechanism in Sects. 3.3 and 4.

When decomposing the changes in total Arctic Ocean heat transport between the sensitivity experiments and the CTRL run into changes due to velocity, temperature and their covariance, the temperature and velocity-temperature covariance components are the main contributors, with about the same contribution for the two (Fig. 3). This means that the major part of the changes in ocean heat transport comes from the changes in ocean temperature. This is expected due to the nature of the sensitivity experiments, where the SST is restored. Figure 3 confirms that the increase in ocean heat transport is larger in the wide domain experiments (compared to the smaller domain experiments) and with a higher level of warming. Overall, the changes in ocean heat transport are larger in the Atlantic experiments compared to the Pacific experiments. This is explained by the large increase in the ocean heat transport at the Barents Sea Opening in the Atlantic experiments (Table 1).

Despite the general increase in ocean heat transport at all Arctic straits (except Davis Strait), the spatial distribution of horizontal ocean heat flux reveals large heterogeneity north of $40^{\circ} \mathrm{N}$ (Fig. 4). Two regions show a marked increase in horizontal ocean heat flux in all experiments: these are the 

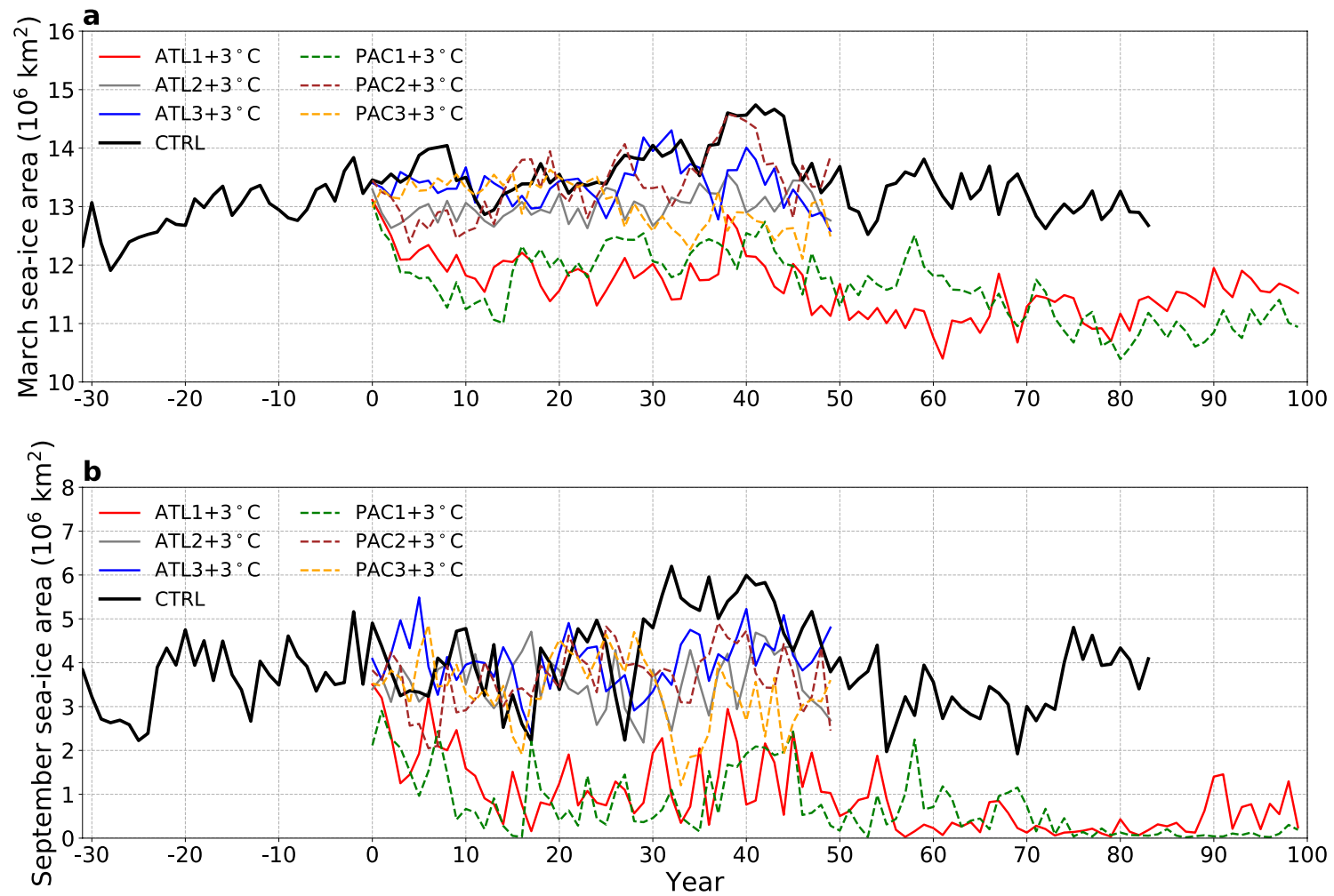

Fig. 5 Time series of Arctic sea-ice area in (a) March and (b) September for the CTRL run and SST $+3{ }^{\circ} \mathrm{C}$ experiments. Year 0 corresponds to the year from which the sensitivity experiments are started

Barents Sea and the Bering/Chukchi Seas. The increase in ocean heat flux in these two regions is more pronounced in the wide domain experiments (ATL1 and PAC1, Fig. 4b,e). The wide and medium-sized domain experiments also show a region of ocean heat flux decrease between 40 and $50^{\circ} \mathrm{N}$ in the North Atlantic. This band of heat flux decrease is linked to the weakening of the AMOC by up to $3 \mathrm{~Sv}$ south of $60^{\circ} \mathrm{N}$ in these experiments (Table 2). The Atlantic Ocean warming of these experiments is responsible for the AMOC weakening. No substantial change in the AMOC is found in the small domain experiments, probably due to the fact that the applied perturbations do not create SST anomalies and associated buoyancy fluxes in regions that are sensitive to the AMOC.

Following the large increase in ocean heat transport (Fig. 2) and horizontal ocean heat flux in the Barents Sea and Bering/Chukchi Seas (Fig. 4) in the wide domain experiments, the Arctic sea-ice edge considerably retreats in these experiments (Fig. 4b, e). The retreat of the sea-ice edge is less pronounced in the other experiments (Fig. 4c, d, f, g). The next section will illustrate in more details the changes in Arctic sea ice in these experiments.

\subsection{Arctic sea ice}

Figure 5 shows the time evolution of March and September Arctic sea-ice area from 30 years before the start of sensitivity experiments up to 100 years after this start. The mean March and September sea-ice areas in the CTRL run, averaged over the 50-year reference period, are $13.7 \pm 0.5$ million $\mathrm{km}^{2}$ and $4.4 \pm 1.0$ million $\mathrm{km}^{2}$, respectively. The mean March and September sea-ice volumes for this CTRL run are $25.9 \pm 3.4 \times 10^{3} \mathrm{~km}^{3}$ and $11.4 \pm 3.7 \times 10^{3} \mathrm{~km}^{3}$, respectively. These values are close to OSI SAF observations for sea-ice area (Lavergne et al. 2019) and PIOMAS reanalysis for seaice volume (Schweiger et al. 2011), well within the bounds of observed interannual variability (Table 2). Note that the CTRL run stops 83 years after the start of these experiments (as the sensitivity experiments start in year 117 of the CTRL run and the entire duration of the latter is 200 years).

The Arctic sea-ice area strongly decreases in both March and September in the two wide domain experiments (ATL1 and PAC1; Fig. 5 and Table 2). We have prolonged the duration of these two experiments by 50 years compared to the other experiments to check the behavior of the sea-ice area in these more extreme experiments; we can see that the sea-ice area stabilizes at a significantly lower level compared to the CTRL run (Fig. 5). In the medium-sized (ATL2 and 
Table 2 Mean Arctic sea-ice area (SIA) and volume (SIV) in March and September, as well as Atlantic Meridional Overturning Circulation index at $26.5^{\circ} \mathrm{N}$ (AMOC), averaged over 50 years, for the CTRL run and the $6 \mathrm{SST}+3^{\circ} \mathrm{C}$ sensitivity experiments

\begin{tabular}{llllll}
\hline Experiment & $\begin{array}{l}\text { March SIA } \\
\left(10^{6} \mathrm{~km}^{2}\right)\end{array}$ & $\begin{array}{l}\text { Sept. SIA } \\
\left(10^{6} \mathrm{~km}^{2}\right)\end{array}$ & $\begin{array}{l}\text { March SIV } \\
\left(10^{3} \mathrm{~km}^{3}\right)\end{array}$ & $\begin{array}{l}\text { Sept. SIV } \\
\left(10^{3} \mathrm{~km}^{3}\right)\end{array}$ & $\begin{array}{l}\text { AMOC } \\
(\mathrm{Sv})\end{array}$ \\
\hline CTRL & $13.7 \pm 0.5$ & $4.4 \pm 1.0$ & $25.9 \pm 3.4$ & $11.4 \pm 3.7$ & $15.5 \pm 2.7$ \\
Observations & $14.0 \pm 0.4$ & $5.2 \pm 1.0$ & $26.3 \pm 3.4$ & $10.7 \pm 4.1$ & $17.5 \pm 1.4$ \\
$\mathrm{ATL} 1+3{ }^{\circ} \mathrm{C}$ & $11.9 \pm 0.4$ & $1.4 \pm 0.8$ & $15.7 \pm 2.2$ & $2.9 \pm 1.8$ & $12.8 \pm 3.0$ \\
$\mathrm{ATL} 2+3{ }^{\circ} \mathrm{C}$ & $13.0 \pm 0.2$ & $3.6 \pm 0.6$ & $22.5 \pm 1.6$ & $8.5 \pm 1.9$ & $14.5 \pm 2.6$ \\
$\mathrm{ATL} 3+3{ }^{\circ} \mathrm{C}$ & $13.4 \pm 0.4$ & $4.0 \pm 0.6$ & $23.5 \pm 1.6$ & $9.5 \pm 2.0$ & $15.8 \pm 2.7$ \\
$\mathrm{PAC} 1+3{ }^{\circ} \mathrm{C}$ & $12.0 \pm 0.4$ & $1.1 \pm 0.8$ & $15.2 \pm 2.1$ & $2.2 \pm 1.6$ & $13.6 \pm 2.8$ \\
$\mathrm{PAC} 2+3{ }^{\circ} \mathrm{C}$ & $13.4 \pm 0.5$ & $3.7 \pm 0.7$ & $22.6 \pm 2.1$ & $8.4 \pm 2.0$ & $14.6 \pm 2.8$ \\
$\mathrm{PAC} 3+3{ }^{\circ} \mathrm{C}$ & $13.0 \pm 0.4$ & $3.4 \pm 0.8$ & $21.2 \pm 2.0$ & $7.2 \pm 2.0$ & $16.2 \pm 2.6$
\end{tabular}

The number after the \pm sign is the standard deviation of the SIA, SIV and AMOC, which represents the interannual variability over the 50 years. If the difference between the sensitivity experiment and the CTRL run is not significant (5\% level), the SIA/SIV/AMOC is indicated in italic. We also provide OSI-450 observations for SIA (mean over 1979-2015, Lavergne et al. (2019)), PIOMAS reanalysis for SIV (mean over 1979-2019, Schweiger et al. (2011)) and RAPID array observations for AMOC (mean over 2005-2017, Smeed et al. (2019)) for comparison
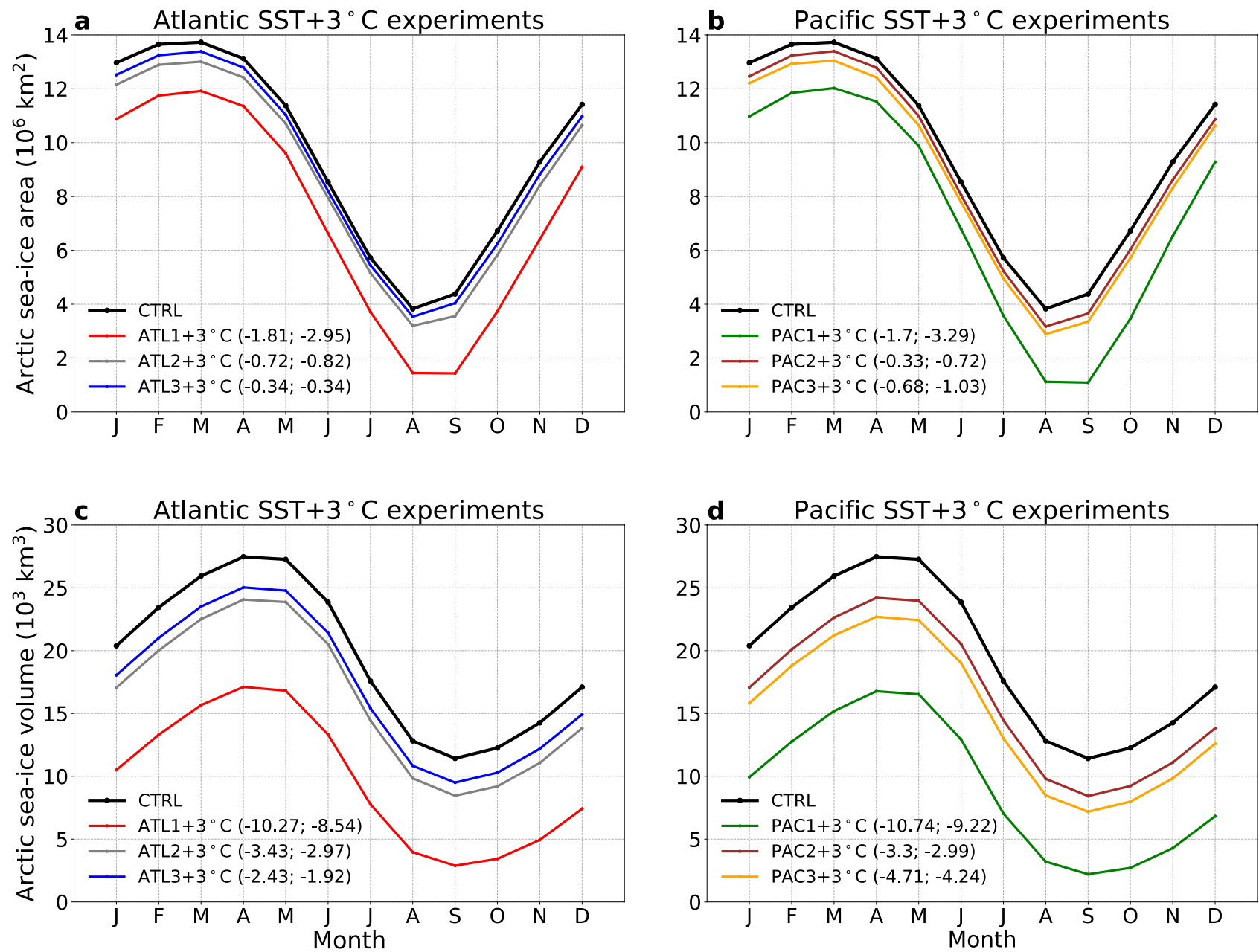

Fig. 6 Mean seasonal cycles of (a, b) Arctic sea-ice area and (c, d) volume for the CTRL run, (a, c) Atlantic and (b, d) Pacific SST $+3{ }^{\circ} \mathrm{C}$ experiments. The two numbers in brackets in the legend are the dif-

ferences in mean March and September (respectively) sea-ice area/ volume between the experiment and the CTRL run 

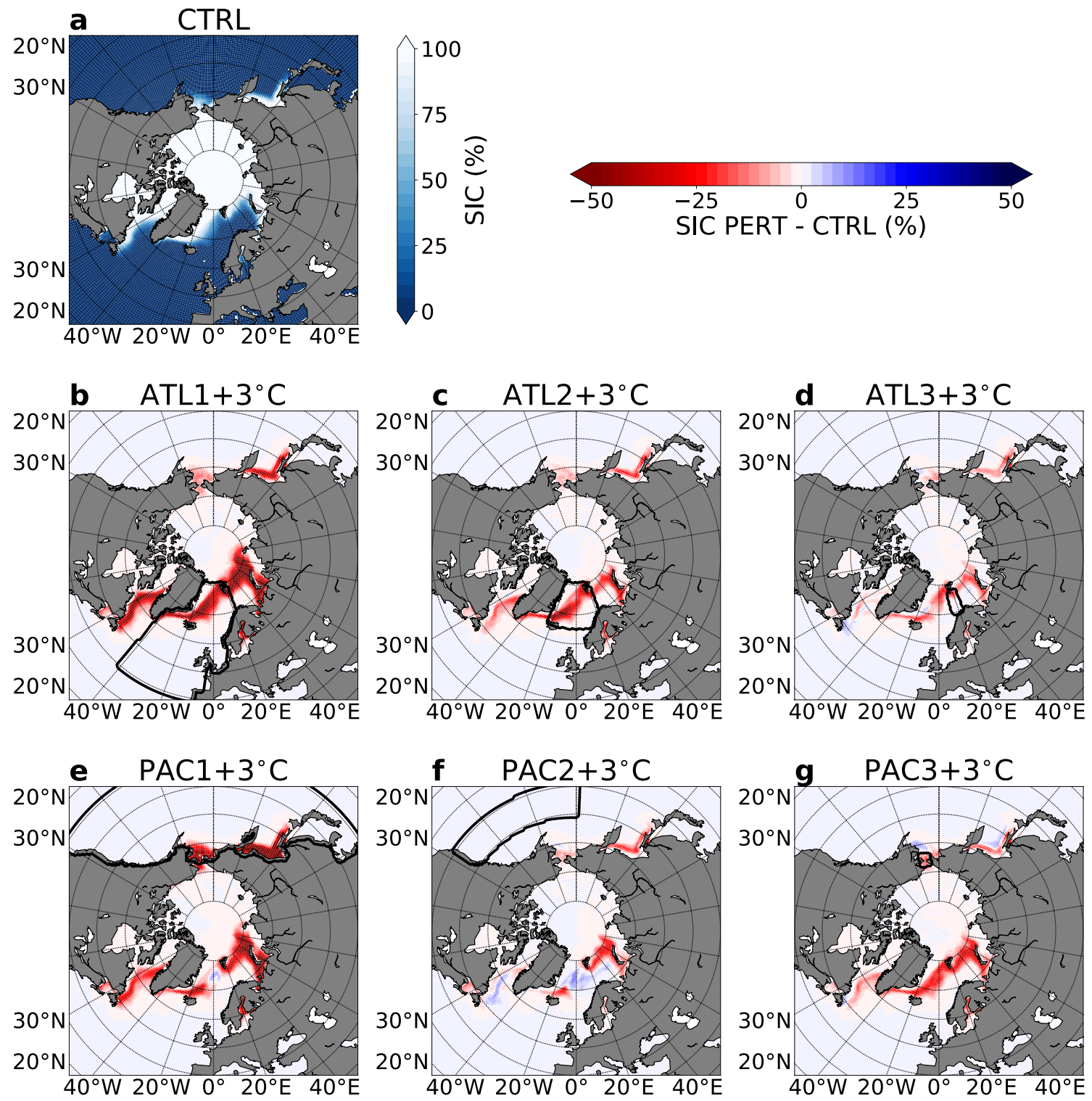

Fig. 7 a Map of mean March sea-ice concentration (SIC, 50-year average) for the CTRL run. b-g Maps of difference in mean March SIC (50-year average) between the Atlantic (middle row)/Pacific (bot-

PAC2) and small (ATL3 and PAC3) domain experiments, the sea-ice area also decreases overall, although this reduction is less pronounced than in ATL1 and PAC1 (Fig. 5).

The seasonal cycles of Arctic sea-ice area and volume are relatively similar in the two wide domain experiments (ATL1 and PAC1, Fig. 6). This suggests that there is no substantial difference in sea ice whether the SST anomaly is imposed in the Atlantic or the Pacific Ocean. In these two wide domain experiments, the sea-ice area loss, compared to the CTRL run, is $\sim 1.8$ million $\mathrm{km}^{2}$ in March and $\sim 3$ million $\mathrm{km}^{2}$ in September (Fig. 6a, b), and the sea-ice volume loss is $\sim 10,000 \mathrm{~km}^{3}$ in March and $\sim 9000 \mathrm{~km}^{3}$ in September (Fig. 6c, d). Thus, the loss in sea-ice area is stronger in tom row) $\mathrm{SST}+3{ }^{\circ} \mathrm{C}$ experiments (PERT) and the CTRL run. The domain in which the SST restoring is applied is shown as a black box for each experiment

summer compared to winter, and the loss in sea-ice volume is larger in winter relative to summer.

In the medium-sized and small domain experiments, there is also an overall decrease in sea-ice area and volume but with a much lower magnitude. Again, in these experiments, the sea-ice area loss is greater in summer and the sea-ice volume loss is stronger in winter (Fig. 6). There is a simple explanation for such a seasonal difference between sea-ice area and volume changes. The sea-ice area loss is stronger in summer compared to winter mainly due to the positive ice-albedo feedback, which leads to rapid ice melting in regions of low sea-ice concentration in summer (Massonnet et al. 2018). The sea-ice volume loss is stronger in winter 

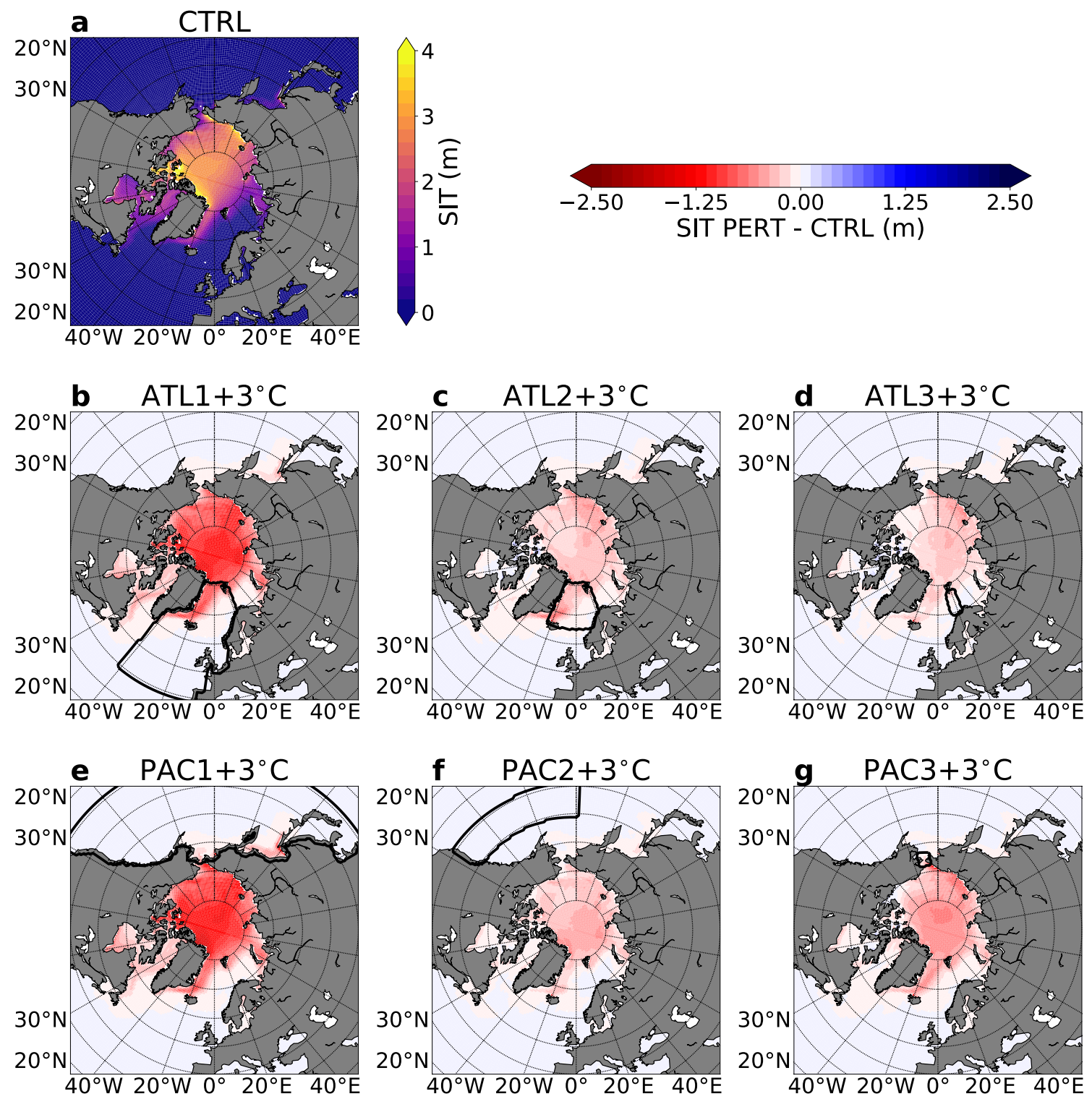

Fig. 8 a Map of mean March sea-ice thickness (SIT, 50-year average) for the CTRL run. b-g Maps of difference in mean March SIT (50year average) between the Atlantic (middle row)/Pacific (bottom row)

compared to summer mainly due to an additional negative feedback, i.e. the ice-growth feedback: as the heat conduction fluxes are larger through thinner sea ice, sea ice at the end of summer grows faster than during winter, when the ice is thicker (Massonnet et al. 2018).

Overall, the decreases in Arctic sea-ice area and volume compared to the CTRL run are larger with a wider SST restoring domain (Table 2), with a few exceptions. The decrease in sea-ice area and volume in $\mathrm{PAC} 2+3{ }^{\circ} \mathrm{C}$ is lower than in PAC $3+3{ }^{\circ} \mathrm{C}$, in agreement with a lower total ocean heat transport in PAC $2+3{ }^{\circ} \mathrm{C}$ (Table 1), but the difference between the two experiments is relatively small. The
SST $+3{ }^{\circ} \mathrm{C}$ experiments (PERT) and the CTRL run. The domain in which the SST restoring is applied is shown as a black box for each experiment

Arctic sea-ice area and volume decreases are also generally enhanced with a higher warming level (not shown).

The spatial distribution of March sea-ice concentration change is relatively similar in the different experiments, with larger loss at the sea-ice edge (Fig. 7). Note the small increase in March sea-ice concentration in the GIN and Labrador Seas in PAC $2+3{ }^{\circ} \mathrm{C}$ (Fig. 7f), which leads to the smaller loss of Arctic sea-ice area in this experiment compared to $\mathrm{PAC} 3+3{ }^{\circ} \mathrm{C}$ (Fig. 6b). The spatial distribution of September sea-ice concentration change is more homogeneous through the Arctic than in March, and again the loss is generally greater with a higher level of warming (not shown). 

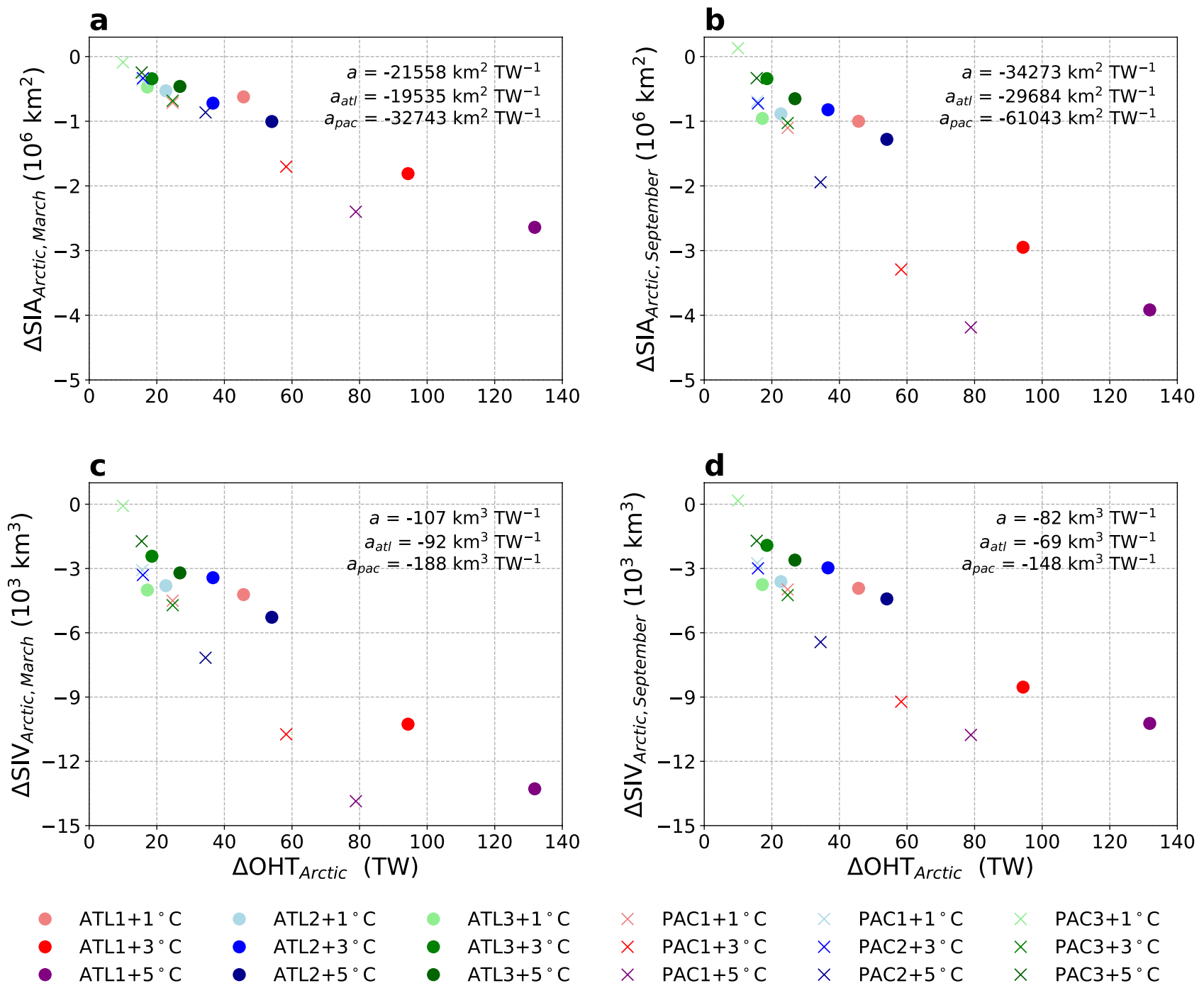

$x$
$\times$
$\times$

$\mathrm{PACl}+1^{\circ} \mathrm{C}$
$\mathrm{PAC} 1+3^{\circ} \mathrm{C}$
$\mathrm{PAC} 1+5^{\circ} \mathrm{C}$

$\mathrm{PAC} 1+1^{\circ} \mathrm{C}$
$\mathrm{PAC} 2+3^{\circ} \mathrm{C}$
$\mathrm{PAC} 2+5^{\circ} \mathrm{C}$

$\mathrm{PAC} 3+1^{\circ} \mathrm{C}$

$\mathrm{PAC} 3+3^{\circ} \mathrm{C}$

$\mathrm{PAC} 3+5^{\circ} \mathrm{C}$

Fig. 9 Change in mean (a) March and (b) September Arctic sea-ice area $(\Delta$ SIA) vs. change in mean ocean heat transport $(\Delta \mathrm{OHT})$ through all Arctic straits between each sensitivity experiment and the CTRL run (1 point for each sensitivity experiment; the dots are for Atlantic experiments and the crosses are for Pacific experiments). c, d Are

The spatial distribution of March (and September, not shown) sea-ice thickness is relatively similar in the different experiments, with larger sea-ice thickness reductions in the wide domain experiments (Fig. 8). The spatial distribution of sea-ice thickness loss is relatively homogeneous, with all Arctic regions experiencing a decrease in thickness. The next section is dedicated to the study of the impact of ocean heat transport on Arctic sea ice.

\subsection{Impact of ocean heat transport on Arctic sea ice}

Figure 9 shows that the loss of Arctic sea-ice area and volume, compared to the CTRL run, is larger with increased ocean heat transport through all Arctic straits. The loss

similar to (a) and (b), respectively, with Arctic sea-ice volume ( $\Delta$ SIV) instead of SIA. The regression slopes $a, a_{a t l}$ and $a_{p a c}$ between the change in SIA/SIV and the change in OHT taking into account all model experiments, Atlantic experiments (dots) and Pacific experiments (crosses), respectively, are provided in each panel

of sea-ice area for a given amount of ocean heat transport increase is larger in September $\left(34,273 \mathrm{~km}^{2} \mathrm{TW}^{-1}\right.$, Fig. $\left.9 \mathrm{~b}\right)$ compared to March $\left(21,558 \mathrm{~km}^{2} \mathrm{TW}^{-1}\right.$, Fig. 9a). On the contrary, the loss of Arctic sea-ice volume is larger in March $\left(107 \mathrm{~m}^{3} \mathrm{TW}^{-1}\right.$, Fig. $\left.9 \mathrm{c}\right)$ compared to September $\left(82 \mathrm{~km}^{3}\right.$ $\mathrm{TW}^{-1}$, Fig. 9d). This is in agreement with the results found in the seasonal cycles of Arctic sea-ice area and volume (Fig. 6).

The loss of Arctic sea-ice area and volume for a same amount of total Arctic Ocean heat transport increase is stronger in the Pacific experiments (crosses in Fig. 9) compared to the Atlantic experiments (dots in Fig. 9). This suggests that a change in ocean heat transport driven by warmer Pacific Ocean temperatures is more effective at 
melting Arctic sea ice than a change in ocean heat transport led by warmer Atlantic water. This result is in agreement with Koenigk and Brodeau (2014), who find that the increase in ocean heat transport at the Bering Strait affects more sea-ice basal melt than the increase in ocean heat transport at the Barents Sea Opening. However, we need to keep in mind that the ocean heat transport at the Bering Strait is $\sim 5$ times lower than the heat transport through the Barents Sea Opening (Table 1), and that the latter also increases in the Pacific experiments, but with a lower magnitude than in the Atlantic experiments (Table 1). Although the total increase in ocean heat transport is generally weaker in the Pacific experiments compared to the Atlantic experiments, the sensitivity of sea-ice area and volume to ocean heat transport increase is stronger in the Pacific experiments, which provides similar amounts of sea-ice loss in both the Atlantic and Pacific experiments (Fig. 9). This will be further discussed below and in Sect. 4.

Also, the higher the level of warming for a same SST restoring region, the larger the increase in ocean heat transport and the larger the loss in Arctic sea-ice area and volume for the wide and medium-sized domain experiments (Fig. 9). The small domain experiments (ATL3 and PAC3) do not show such a clear scaling with the level of warming, but the changes in ocean heat transport and sea-ice area and volume are much lower than in the wide and medium-sized domain experiments. Figure 9 also confirms that a larger SST restoring region generally leads to a larger increase in ocean heat transport and a larger loss in sea-ice area and volume for a same level of warming.

As previously discussed in Sect. 3.1, the increase in ocean heat transport in our sensitivity experiments mainly comes from ocean temperature changes rather than ocean velocity changes (Fig. 3). Therefore, in order to understand the impact of the changes in ocean heat transport on sea ice we now look at how the ocean temperature varies across the first $1000 \mathrm{~m}$ (where most changes happen). Figure 10 shows the vertical profiles of mean ocean temperature changes for the SST $+3{ }^{\circ} \mathrm{C}$ experiments compared to the CTRL run, averaged over the Arctic Ocean for each latitude for both the Atlantic and Pacific sides. It shows that the ocean temperature clearly increases in the upper $600-800 \mathrm{~m}$, with a maximum of up to $2-3{ }^{\circ} \mathrm{C}$ around $200 \mathrm{~m}$ depth, in the wide and medium-sized domain experiments (Fig. 10b, c, e, f, i, $\mathrm{j}, \mathrm{l}, \mathrm{m})$. The temperature increase is more pronounced and reaches deeper ocean levels in the wide domain experiments (ATL1 and PAC1) compared to the medium-sized domain experiments.

Interestingly, we note a cooling on the Atlantic side below $600-800 \mathrm{~m}$ in the wide and medium-sized domain experiments, between $60^{\circ} \mathrm{N}$ and $80^{\circ} \mathrm{N}$ (Fig. 10b, c, e, f). Thus, the contrast between the large increase in ocean temperature in the top layers and the decrease in temperature at deeper levels leads to enhanced stratification of the Arctic and northern Atlantic Oceans, leading to reduced AMOC in the wide and medium-sized experiments (Table 2).

An increase in ocean temperature is also present in the small domain experiments (Fig. 10d, g, k, n), but the strength of this increase is much weaker compared to the other experiments and the temperature increase is confined to the upper layers. The comparison of PAC $2+3{ }^{\circ} \mathrm{C}$ (Fig. 10f, m) and PAC $3+3{ }^{\circ} \mathrm{C}$ (Fig. $10 \mathrm{~g}, \mathrm{n}$ ) shows that the ocean temperature increase reaches deeper levels in the former experiment, but the increase at the surface is higher in the latter experiment. This result partly explains why the Arctic sea-ice area and volume losses are larger in PAC $3+3{ }^{\circ} \mathrm{C}$ compared to PAC $2+3{ }^{\circ} \mathrm{C}$ (Fig. 6b, d).

We previously identified a more effective melting of Arctic sea ice with a same amount of ocean heat transport in the Pacific experiments (Fig. 9). Figure 10i-n shows that the ocean temperatures are warmer in the surface layers in the Bering Sea, Bering Strait and Chukchi Sea in the Pacific experiments compared to the Atlantic experiments. This is particularly obvious for the wide domain experiments: $\mathrm{PAC} 1+3{ }^{\circ} \mathrm{C}$ has much warmer temperatures in the Bering Sea and Strait than ATL $1+3{ }^{\circ} \mathrm{C}$, which leads to stronger sea-ice melting in this region in $\mathrm{PAC} 1+3{ }^{\circ} \mathrm{C}$ (Fig. 7). On the Atlantic side, near-surface ocean temperatures are warmer in the Atlantic experiments (Fig. 10b-g).

To identify the exact process by which the ocean heat contributes to sea-ice melt, we decompose the sea-ice mass balance in its different terms, i.e. basal growth, open-water growth, dynamic growth, snow-ice formation, basal melt and surface melt. The EC-Earth3 model outputs do not contain lateral melt, but this process is minor compared to other processes (Keen et al. 2020). Figure 11 shows the different components of the sea-ice mass balance as well as the net sea-ice growth for the CTRL run (Fig. 11a), as well as the changes in these components in the different sensitivity experiments compared to the CTRL run (Fig. 11b-g), for the whole Arctic and averaged over the 50-year reference period. We find that Arctic sea ice mainly grows via basal growth $\left(62 \mathrm{~cm}\right.$ year $\left.{ }^{-1}\right)$ and open-water growth $\left(31 \mathrm{~cm} \mathrm{year}^{-1}\right)$, while it mostly melts from basal melt $\left(-83 \mathrm{~cm} \mathrm{year}^{-1}\right)$ and surface melt $\left(-20 \mathrm{~cm} \mathrm{year}^{-1}\right)$ in the CTRL run (Fig. 11a). The respective contribution from these different terms is overall in agreement with previous modeling studies (Rousset et al. 2015; Tsamados et al. 2015; Keen et al. 2020).

The net sea-ice melt coming from our sensitivity experiments ranges between almost no change in ATL $3+3{ }^{\circ} \mathrm{C}$ (Fig. 11d) and $\sim 1.5 \mathrm{~cm} \mathrm{year}^{-1}$ in ATL $1+3{ }^{\circ} \mathrm{C}$ (Fig. 11b) and PAC $1+3{ }^{\circ} \mathrm{C}$ (Fig. 11e), relative to the CTRL run. In ATL $1+3{ }^{\circ} \mathrm{C}$ and PAC $1+3{ }^{\circ} \mathrm{C}$, the net ice melt is driven by lower basal growth, and to a lesser extent by lower dynamic growth and lower snow-ice formation, compared 

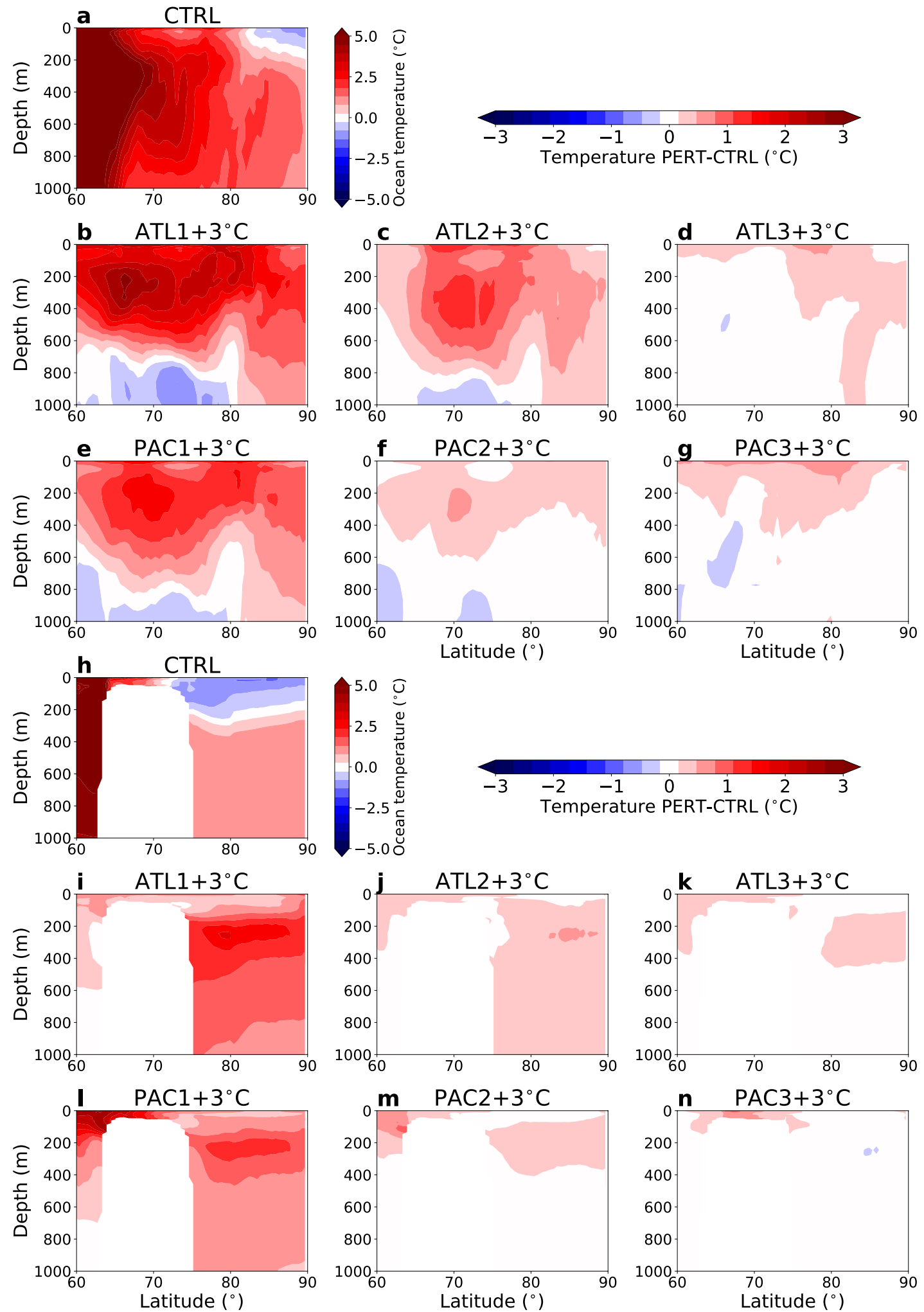

Fig. 10 a Vertical profile of the mean Arctic Ocean temperature for each latitude between 60 and $90{ }^{\circ} \mathrm{N}$ (Atlantic side, including the whole Atlantic basin) for the CTRL run (50-year average). b-g Vertical profiles of the difference in mean Arctic Ocean temperature
(Atlantic side) between the Atlantic (middle row)/Pacific (bottom row) $\mathrm{SST}+3{ }^{\circ} \mathrm{C}$ experiments (PERT) and the CTRL run (50-year average). h Same as (a) for the Pacific side (including the whole Pacific basin). $\mathbf{i}-\mathbf{n}$ Same as (b-g) for the Pacific side 

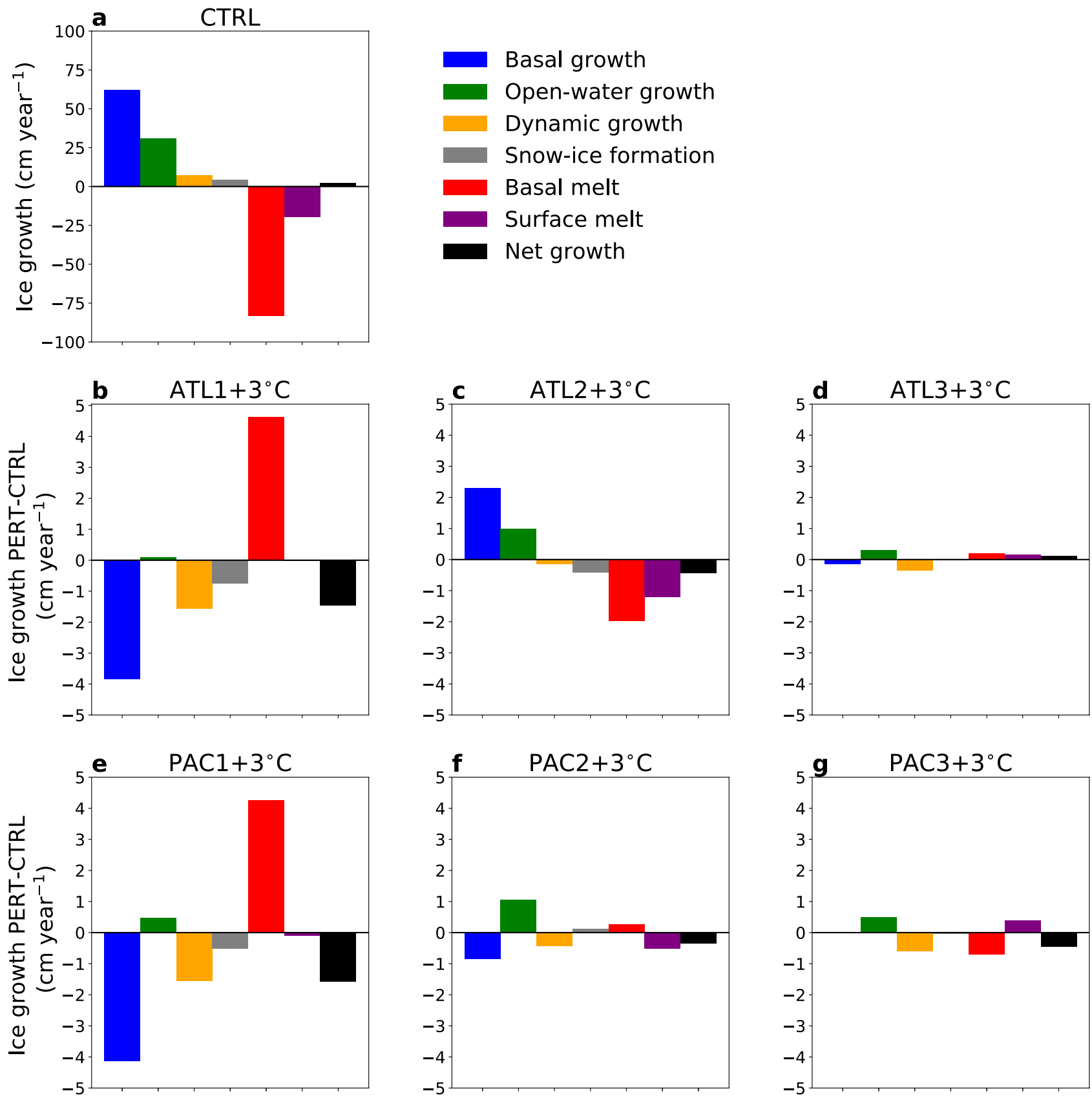

Fig. 11 a Components of the sea-ice mass balance (50-year average over the whole Arctic domain) for the CTRL run. A positive value for a specific process means that sea ice grows due to this specific process. b-g Difference in sea-ice mass balance processes (50-year average over the whole Arctic domain) between the Atlantic (middle

to the CTRL run. The mean basal melt is reduced in these two experiments compared to the CTRL run, which leads to net ice growth from this component. Note that this reduced mean basal melt hides large regional differences between enhanced basal melt in the Central Arctic and reduced basal melt close to the sea-ice edge (Fig. 13b, e). The latter results from a strong reduction in sea-ice
row)/Pacific (bottom row) $\mathrm{SST}+3{ }^{\circ} \mathrm{C}$ experiments (PERT) and the CTRL run. A positive value means that sea ice grows due to this specific process relative to the CTRL run. In all computations, we take all grid points for which sea-ice concentration is strictly greater than 0

concentration at the sea-ice edge, making much less sea ice available for being melted, in agreement with Sando et al. (2014). The net ice melt is relatively similar in both ATL $1+3{ }^{\circ} \mathrm{C}$ and PAC $1+3{ }^{\circ} \mathrm{C}$, which leads to similar amounts of sea-ice loss in these two experiments (Fig. 6). In ATL $2+3{ }^{\circ} \mathrm{C}$, the net sea-ice melt is driven by stronger basal and surface melts, relative to the CTRL run (Fig. 
11c). In $\mathrm{PAC} 2+3{ }^{\circ} \mathrm{C}$, the net melt is driven by lower basal and dynamic growths and larger surface melt (Fig. 11f). In PAC $3+3{ }^{\circ} \mathrm{C}$, the net melt is driven by stronger basal melt and lower dynamic growth (Fig. 11g).

The net sea-ice mass balance varies with space. In the CTRL run, there is a net ice growth in the Central Arctic and along the coastlines of Siberia, north Greenland and part of Canada, while there is a net ice melt along the sea-ice edge (Fig. 12a). All sensitivity experiments result in a lower sea-ice growth (so more melt) in most parts of the Central Arctic, Kara and Bering/Chukchi Seas, and a lower sea-ice melt close to the sea-ice edge and along several coastlines, relative to the CTRL run (Fig. 11b-g). These changes are stronger in the wide domain experiments (Fig. 11b, e) and with a higher level of warming (not shown).

Interestingly, the changes in net sea-ice growth/melt (Fig. 12) correspond very well to the changes in sea-ice basal melt (Fig. 13), with larger basal melt in the Central Arctic and reduced basal melt along the sea-ice edge. Together with reduced basal growth along the sea-ice edge (especially in the Barents-Kara Sea, not shown), this agrees with Sando et al. (2014). Also, the orders of magnitude of net growth/ melt and basal melt are very similar. The other sea-ice mass balance components do not show such a high spatial correspondence with the net sea-ice growth/melt. This indicates that basal melt is an important process in controlling the changes in sea ice that occur in the course of our sensitivity experiments, implying a strong influence of the ocean heat transport.

\section{Discussion}

Our analysis is in line with previous modeling studies, showing a strong connection between enhanced ocean heat transport and decreasing Arctic sea ice (e.g. Mahlstein and Knutti 2011; Sando et al. 2014; Li et al. 2017; Muilwijk et al. 2019; see Sect. 1). The main novelty of our study is to have built experiments in which we can separate the impact of imposing SST anomalies in the Atlantic Ocean from the effect of imposing them in the Pacific Ocean. In this respect, we find that the overall reduction of Arctic sea-ice area/volume is similar whether the Atlantic or the Pacific is warmed up (Fig. 6 and Table 2). As the ocean heat transport increase is smaller in the Pacific experiments compared to the Atlantic experiments (Figs. 2, 3 and Table 1), this means that the Pacific experiments are more efficient at melting Arctic sea ice than the Atlantic experiments (Fig. 9).

Two different mechanisms probably explain this more effective role of the Pacific experiments. First, the warm water transported through the Bering Strait has a lower salinity than the Atlantic Water and then stays closer to the surface, which would further enhance sea-ice basal melt (Koenigk and Brodeau 2014). Indeed, we see that ocean temperatures are warmer in the Bering Sea, Bering Strait and Chukchi Sea (Fig. 10), and that basal melt is enhanced at the Bering Strait (Fig. 13) in the Pacific experiments, especially in PAC $1+3{ }^{\circ} \mathrm{C}$. However, the near-surface ocean temperatures are warmer on the Atlantic side in the Atlantic experiments, so there must be additional mechanisms explaining the efficiency of the Pacific experiments at melting sea ice.

The second process that could play is the presence of an atmospheric bridge between the North Pacific and North Atlantic Oceans (Liu and Alexander 2007). By design, our experiments directly affect the ocean temperature and heat transport. However, the atmosphere also changes as a response of the imposed SST anomalies. In particular, the surface air temperature increases in the northern hemisphere in all our experiments, with the exception of some areas experiencing a cooling (Central Asia and North America during some months, not shown). Thus, the atmosphere may also play a role in the sea-ice changes that occur in our sensitivity experiments.

Plotting the changes in Arctic sea-ice area and volume against the changes in Arctic surface air temperature, in a similar way as Fig. 9, also provides a strong negative correlation between the two variables, i.e. there is a decrease in sea-ice area/volume with a larger surface air temperature. However, no distinction appears in this relationship between the Atlantic and Pacific experiments, as for the ocean heat transport. Also, due to the strong responses of sea-ice basal melt and basal growth to the changes in SST and relatively weak sea-ice surface melt response (Fig. 11), we think that the ocean plays a larger role than the atmosphere in driving the sea-ice area and volume reductions in our experiments. Thus, the increase in surface air temperature in these experiments plays more as an additional amplifier, through the ice-albedo feedback, rather than a direct cause of sea-ice changes.

Latitudinal transects of the northward atmospheric and ocean heat transports show that the peaks in atmospheric and ocean heat transport occur around $40^{\circ} \mathrm{N}(\sim 5 \mathrm{PW})$ and $15^{\circ} \mathrm{N}$ ( $\sim 2 \mathrm{PW}$ ), respectively (Fig. 14a), in agreement with van der Linden et al. (2019). North of $60^{\circ} \mathrm{N}$, the atmospheric heat transport slightly decreases in all experiments, except in PAC $2+3^{\circ} \mathrm{C}$, compared to the CTRL run (Fig. $14 \mathrm{~b}-\mathrm{c}$ ), while the ocean heat transport increases (Fig. 14d, e). This shows that the Arctic warming in our perturbed experiments is largely dominated by the ocean heat transport.

Although the atmosphere is not directly responsible for the Arctic sea-ice loss in our experiments, its response needs to be taken into account to fully understand the differences between the Atlantic and Pacific experiments. We investigate the role of the atmosphere by looking at the change in net atmospheric surface heat flux (positive downwards) between 
each experiment and the CTRL run (Fig. 15). Without surprise, the regions where the SST is restored (black boxes in Fig. 15b-g) experience a loss in surface heat flux, mainly due to enhanced latent heat flux (and secondarily increased sensible heat flux). Outside of the restoring regions, the most significant and interesting change is an increase in surface heat flux in the North Atlantic Ocean in the PAC $1+3{ }^{\circ} \mathrm{C}$ and PAC $2+3{ }^{\circ} \mathrm{C}$ experiments (Fig. $15 \mathrm{e}, \mathrm{f}$ ). This means that the atmosphere warms the North Atlantic Ocean surface in these two experiments, which leads to enhanced ocean heat transport at the Barents Sea Opening and Fram Strait (Table 1). Note that there is almost no change in the North Pacific net surface heat flux in the Atlantic experiments (Fig. 15b-d).
In the Pacific experiments, each TW increase in the net atmospheric surface heat flux integrated over the North Atlantic leads to a $0.5 \mathrm{TW}$ increase in the ocean heat transport in the Atlantic (sum of Barents Sea Opening and Fram Strait heat transports) on average (regression slope associated with the crosses in Fig. 16a). For example, in the $\mathrm{PAC} 1+3{ }^{\circ} \mathrm{C}$ experiment, the Atlantic atmospheric surface heat flux increases by $59 \mathrm{TW}$ and the Atlantic ocean heat transport is enhanced by $47 \mathrm{TW}$ relative to the CTRL run. In the PAC $2+3{ }^{\circ} \mathrm{C}$ experiment, the increase in the Atlantic surface heat flux is $28 \mathrm{TW}$ and the increase in the Atlantic Ocean heat transport is $14 \mathrm{TW}$. These results suggest that about half the amount of atmospheric surface heat flux
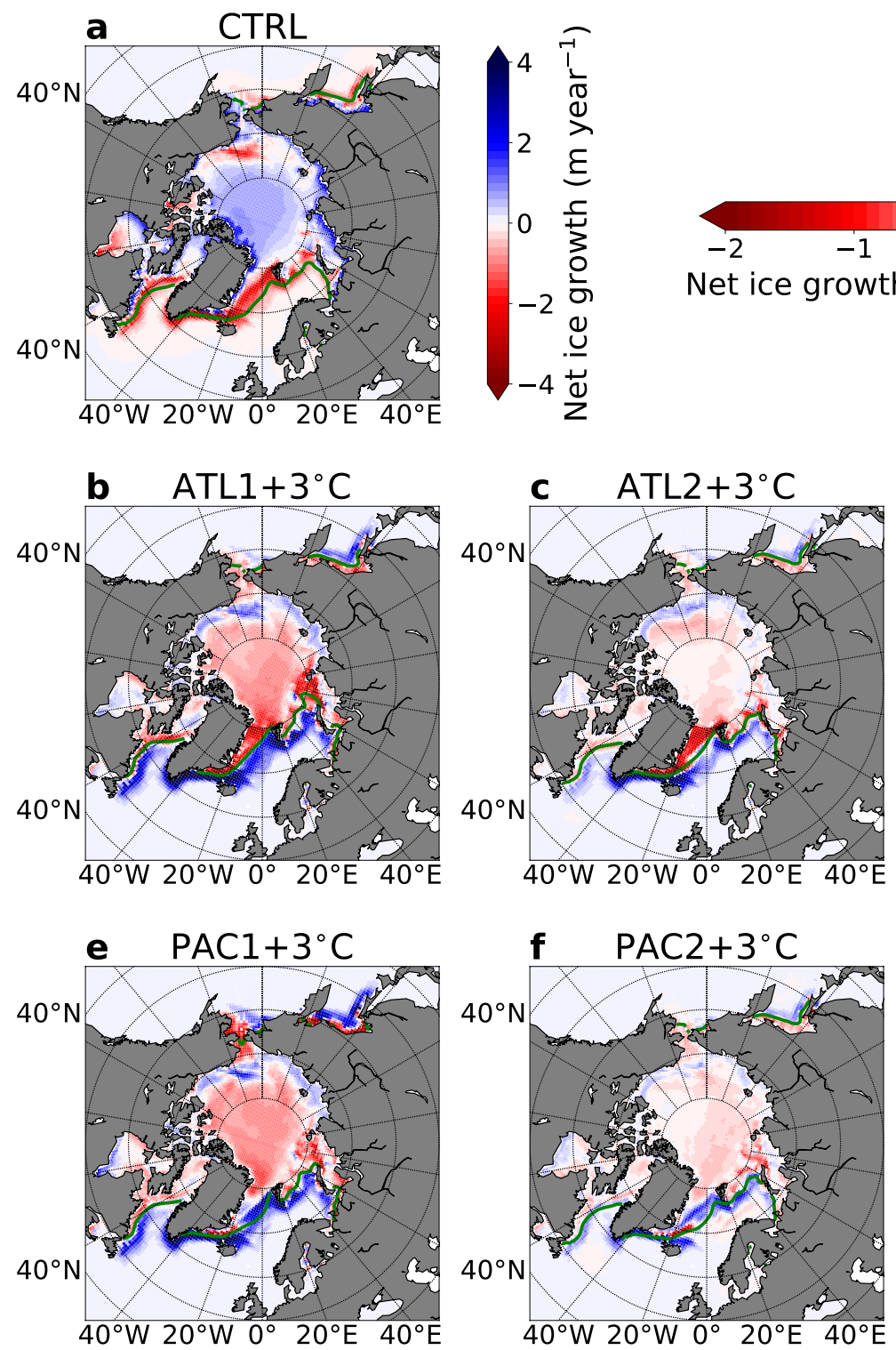
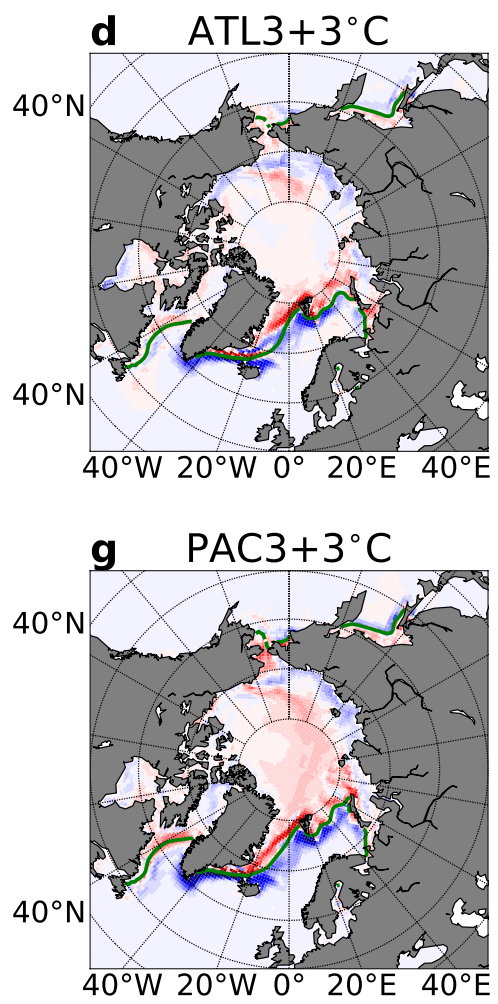

Fig. 12 a Map of mean net sea-ice growth (50-year average) for the CTRL run. b-g Maps of difference in mean net sea-ice growth (50year average) between the Atlantic (middle row) / Pacific (bottom row) $\mathrm{SST}+3{ }^{\circ} \mathrm{C}$ experiments (PERT) and the CTRL run. The green curve shows the mean $15 \%$ sea-ice concentration contour for each different experiment 

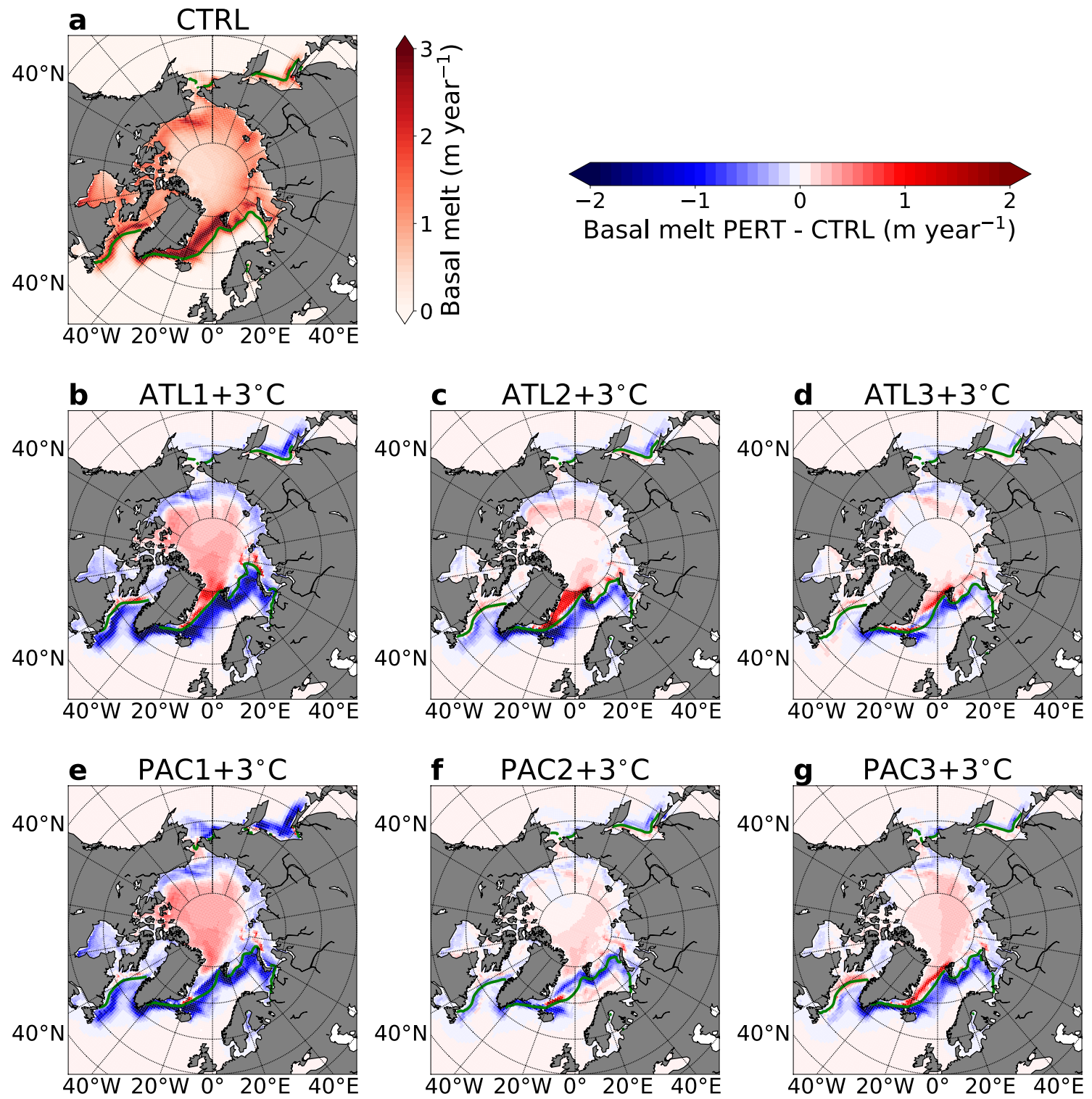

Fig. 13 a Map of mean sea-ice basal melt (50-year average) for the CTRL run. b-g Maps of difference in mean sea-ice basal melt (50year average) between the Atlantic (middle row)/Pacific (bottom row)

gained by the North Atlantic Ocean is used in increasing the ocean heat transport at the Barents Sea Opening and Fram Strait.

In the Atlantic experiments, no significant change in the net atmospheric surface heat flux is found in the North Pacific Ocean, excluding an important role of the atmosphere in driving large changes in ocean heat transport in these experiments (Fig. 15b-d). Contrarily to the Pacific experiments, there is no clear relationship between the
$\mathrm{SST}+3{ }^{\circ} \mathrm{C}$ experiments (PERT) and the CTRL run. The green curve shows the mean $15 \%$ sea-ice concentration contour for each different experiment

changes in the North Pacific atmospheric surface heat flux and the changes in ocean heat transport at the Bering Strait in the Atlantic experiments (dots in Fig. 16b).

Thus, the increase in ocean heat transport on the Atlantic side (Barents Sea Opening and Fram Strait) in the PAC $1+3{ }^{\circ} \mathrm{C}$ and $\mathrm{PAC} 2+3{ }^{\circ} \mathrm{C}$ experiments is linked to atmospheric warming in the North Atlantic, following the SST anomaly imposed in these experiments. The fact that we also see an increase in the ocean heat transport at the Barents Sea Opening in the 

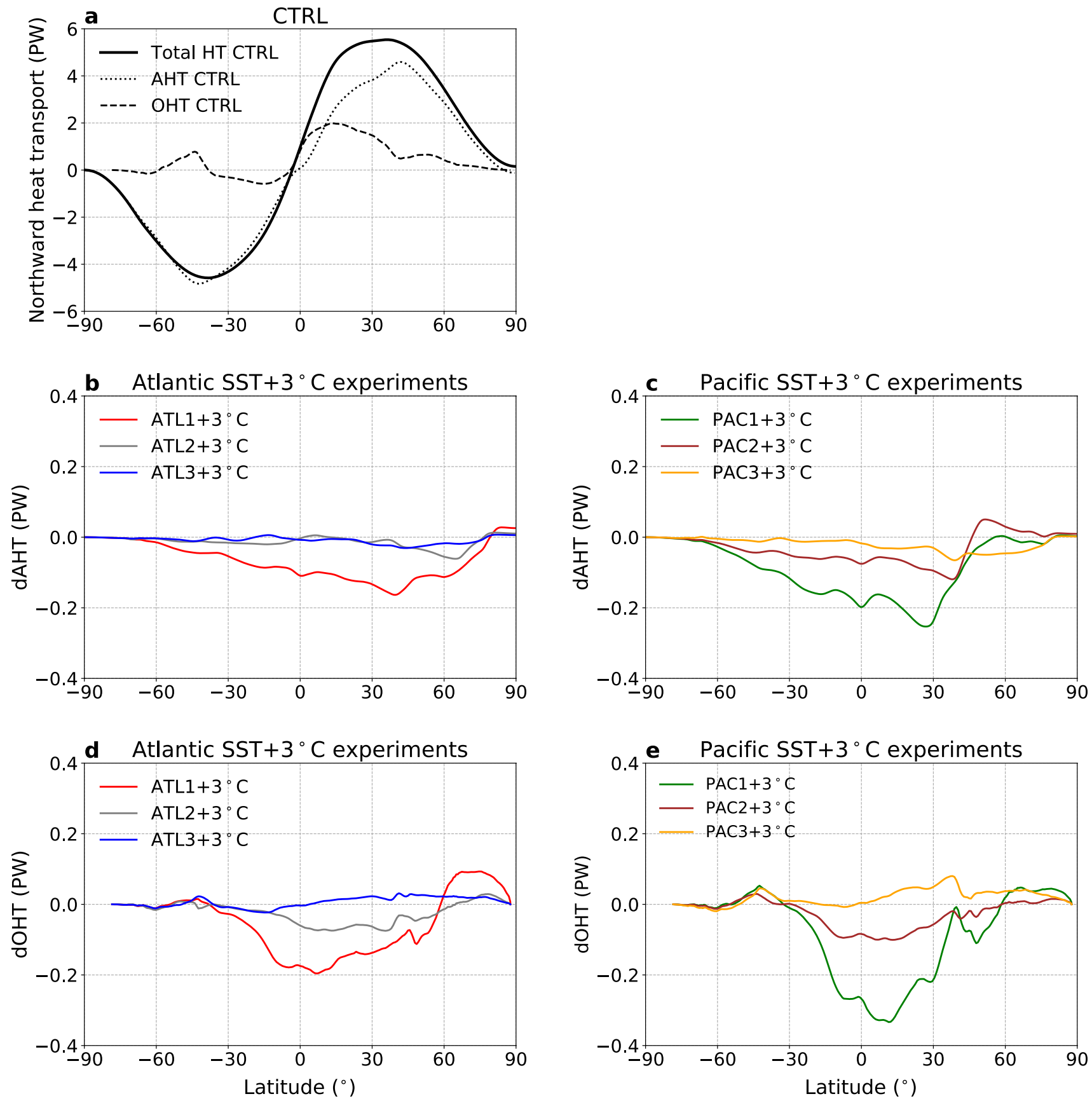

Fig. 14 a Latitudinal transect of northward total, atmospheric (AHT) and ocean (OHT) heat transports for the CTRL run (50-year average). b Latitudinal transect of the difference in northward atmospheric heat

transport between the Atlantic SST $+3{ }^{\circ} \mathrm{C}$ experiments and the CTRL run (50-year average). c Same as (b) for the Pacific SST $+3{ }^{\circ} \mathrm{C}$ experiments. d-e Same as $(\mathbf{b}-\mathbf{c})$ for the northward ocean heat transport

PAC $3+3{ }^{\circ} \mathrm{C}$ experiment without noticing any increase in the net atmospheric heat flux in the North Atlantic (Fig. 15g) is probably linked to internal variability for this specific experiment. As already discussed in Sect. 3.1, the increase in the Barents Sea Opening (and total) ocean heat transport

in the PAC $3+1{ }^{\circ} \mathrm{C}$ and $\mathrm{PAC} 3+5{ }^{\circ} \mathrm{C}$ experiments is not as large as PAC $3+3{ }^{\circ} \mathrm{C}$, and is smaller than in PAC $2+1{ }^{\circ} \mathrm{C}$ and PAC $2+5^{\circ} \mathrm{C}$, respectively (Fig. 3a). 

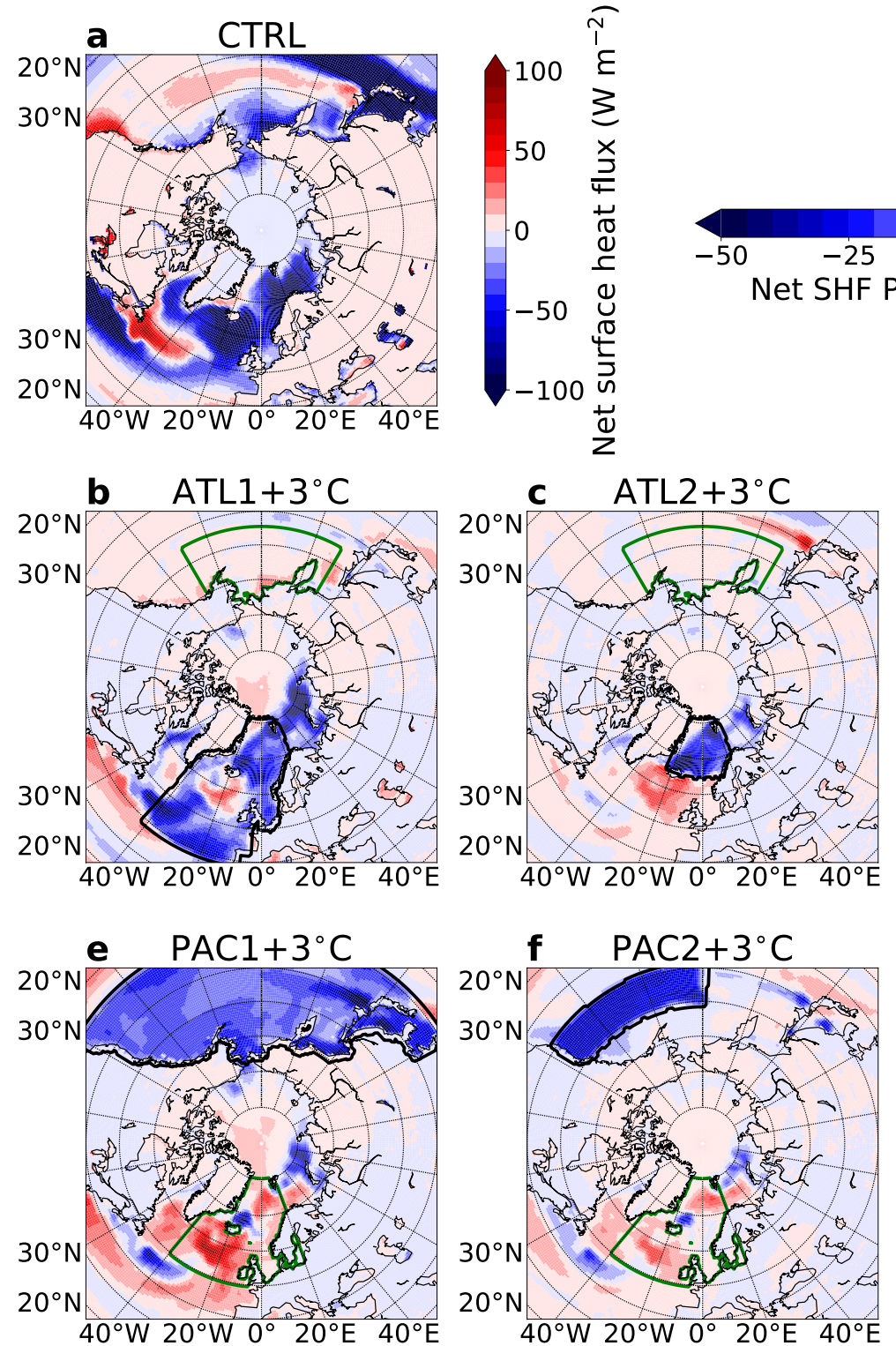
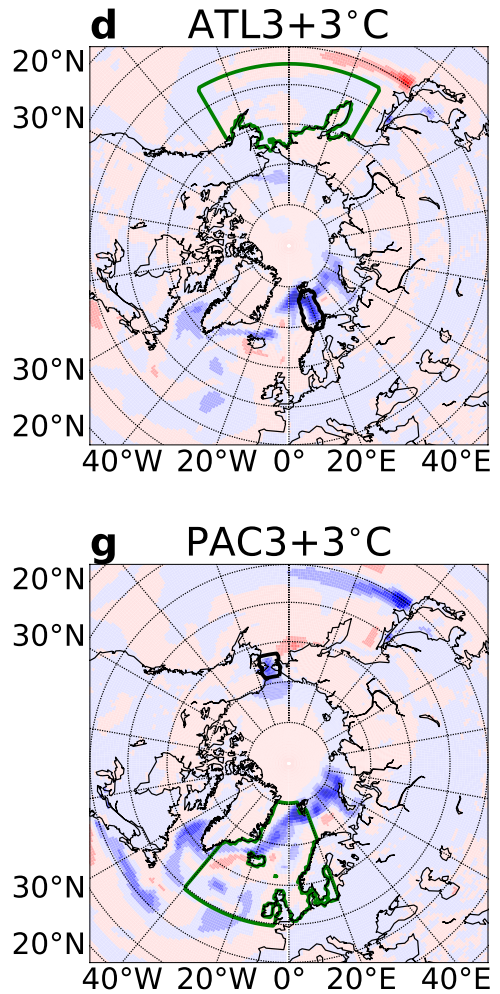

Fig. 15 a Map of mean net atmospheric surface heat flux (50-year average, positive downwards) for the CTRL run. b-g Maps of difference in mean net atmospheric surface heat flux (50-year average) between the Atlantic (middle row) / Pacific (bottom row) SST $+3{ }^{\circ} \mathrm{C}$ experiments (PERT) and the CTRL run. The domain in which the
SST restoring is applied is shown as a black box for each experiment. Also, the domain over which we compute the mean net atmospheric surface heat flux for Fig. 16 is shown as a green box (Pacific domain in b-d and Atlantic domain in $\mathbf{e}-\mathbf{g}$ )

\section{Conclusions}

In this study, we have analyzed the results from 18 different sensitivity experiments and one present-day control run conducted with the coupled global climate model EC-Earth3. In our sensitivity experiments, the SST is artificially increased with three different levels of warming in different regions of the Atlantic and Pacific Oceans. Our main results are:

1. In all sensitivity experiments, the total Arctic Ocean heat transport increases relative to the control run (Table 1,
Figs. 2, 3, 4). This increase is mainly driven by the Barents Sea Opening for the Atlantic experiments and by the Bering Strait and Barents Sea Opening for the Pacific experiments (Table 1). The fact that the ocean heat transport considerably increases at the Barents Sea Opening (and to a lesser extent at the Fram Strait) in the Pacific experiments is related to atmospheric warming in the North Atlantic, through increased downward atmospheric surface heat flux (Figs. 15, 16).

2. In all sensitivity experiments, the Arctic sea-ice area and volume decrease (Table 2, Figs. 5, 6). Interestingly, the 

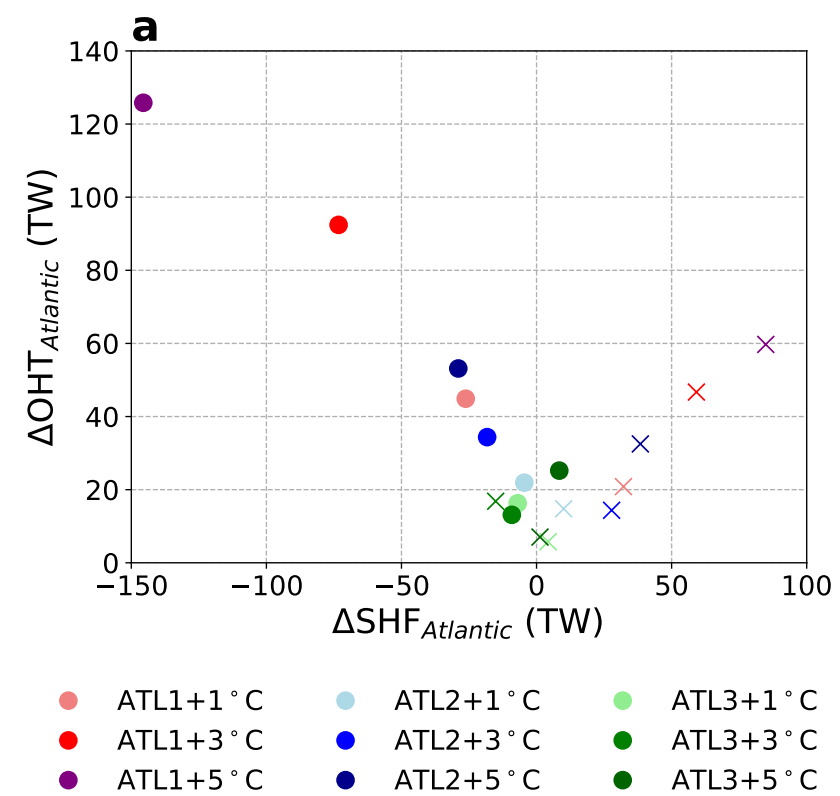

Fig. 16 a Change in mean Atlantic (Barents Sea Opening + Fram Strait) ocean heat transport $\left(\Delta \mathrm{OHT}_{\text {Atlantic }}\right)$ vs. change in mean net atmospheric surface heat flux in the Atlantic $\left(\Delta \mathrm{SHF}_{\text {Atlantic }}\right)$ between each sensitivity experiment and the CTRL run. b Change in mean

loss in sea-ice area and volume is approximately similar in the two wide domain experiments. This suggests that there is no substantial difference in sea ice whether the SST anomaly is imposed in the Atlantic or the Pacific Ocean.

3. In general, the wider the restoring domain and the larger the level of warming, the larger the increase in ocean heat transport and the stronger the loss of Arctic seaice area and volume (Tables 1, 2, Figs. 2, 3, 4, 5, 6, 7, 8). The small domain experiments (SST increase at the Barents Sea Opening and Bering Strait) do not show such a good scaling with a temperature increase, but the changes in ocean heat transport and sea-ice area are lower than for the other experiments.

4. Our sensitivity experiments confirm that the relationship between ocean heat transport and Arctic sea ice is causal: an increased ocean heat transport leads to reduced Arctic sea-ice area. Furthermore, the impact of ocean heat transport on Arctic sea ice is more efficient in the Pacific experiments, relative to the Atlantic experiments: for a same amount of ocean heat transport increase, the loss of sea ice is larger in the Pacific experiments (Fig. 9). This is explained by lower-salinity water at the Bering Strait (staying close to the surface and melting sea ice) and atmospheric warming of the North Atlantic Ocean in the Pacific experiments (Figs. 15, 16).

5. Studying the different components of the sea-ice mass budget allows to show that basal melt increases in the

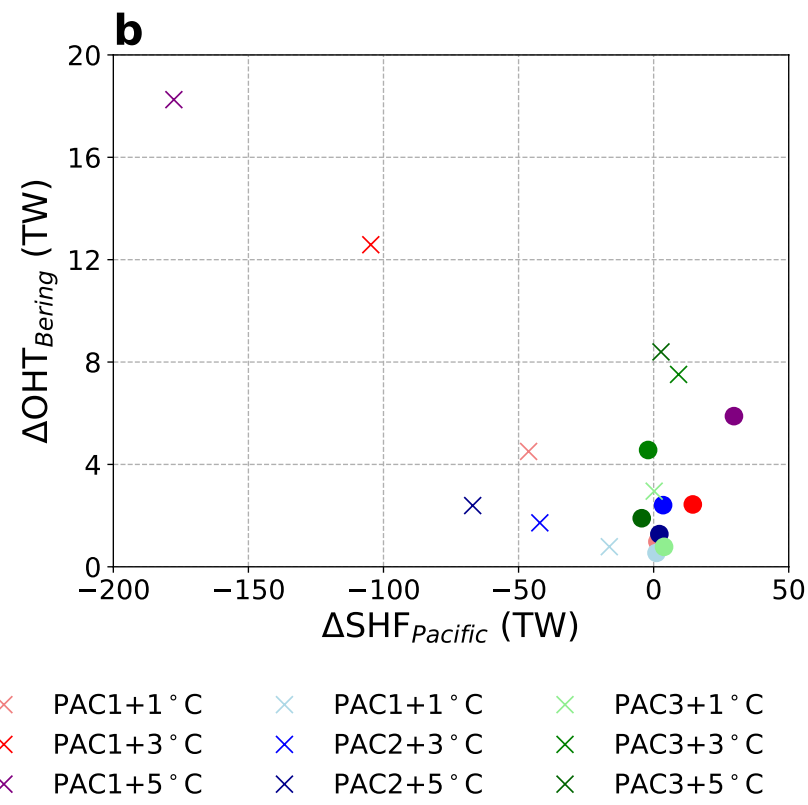

Bering Strait ocean heat transport $\left(\Delta \mathrm{OHT}_{\text {Bering }}\right)$ vs. change in mean net atmospheric surface heat flux in the Pacific $\left(\Delta \mathrm{SHF}_{\text {Pacific }}\right)$ between each sensitivity experiment and the CTRL run

Central Arctic and basal growth is reduced along the sea-ice edge. Also, the spatial changes in net sea-ice growth closely follow the spatial changes in basal melt (Figs. 11, 12, 13). This confirms that the ocean heat transport is the primary driver of Arctic sea-ice loss in these experiments.

With this analysis, we shed some lights on the processes that link ocean heat transport and Arctic sea-ice changes. However, further investigation is needed to clarify the pathways by which sea ice is affected by ocean heat transport. In particular, these experiments were designed to directly affect the ocean heat transport. However, the changes in SST and ocean heat transport also impact the atmosphere. Our experiments show that the atmosphere also plays a role, particularly in warming the Barents Sea in the Pacific experiments. Finally, the use of higher-resolution models would allow to provide a better representation of ocean currents, giving supplementary insights into the ocean-sea ice processes occurring in the Arctic.

Acknowledgements The EC-Earth model simulations were carried out on Tetralith at the National Supercomputer Center (NSC, Linköping University) using resources provided by the Swedish National Infrastructure for Computing S-CMIP project (SNIC 2019/2-8). We thank Michael Sahlin (SMHI) for providing help in using the IT server resources and Klaus Wyser (SMHI) for giving access to the EC-Earth3 historical simulation from which we started our experiments. We thank the three anonymous reviewers for providing insightful comments that helped to improve our paper. We finally thank the Editor J.-C. Duplessy. 
Author Contributions DD and TK designed the study. DD performed the model experiments, analyzed the results and produced the figures. All authors participated to the interpretation and discussion of results. DD led the writing of the manuscript, with contributions from all co-authors.

Funding Information DD is supported by the OSeaIce project (https ://cordis.europa.eu/project/id/834493), which has received funding from the European Union's (EU) Horizon 2020 research and innovation programme under the Marie Sklodowska-Curie grant agreement No. 834493. TK and RFF are funded by the EU Horizon 2020 PRIMAVERA project, grant agreement No. 641727. MPK acknowledges support from the NordForsk research program Arctic Climate Predictions: Pathways to Resilient, Sustainable Societies (ARCPATH, No. 76654). YRR was funded by the EU Horizon 2020 research and innovation programme in the framework of the Marie Sklodowska-Curie grant INADEC (grant agreement No. 800154).

Data Availability Statement The raw model data will be located on the National Supercomputer Center (NSC) tape storage system at Linköping University (https://www.nsc.liu.se/) and will be available upon request. The post-processed data are available on Zenodo: https ://zenodo.org/record/4292003.

\section{Compliance with ethical standards}

Code availability The EC-Earth model is restricted to institutes that have signed a memorandum of understanding or letter of intent with the EC-Earth consortium and a software license agreement with ECMWF. Confidential access to the code can be granted for the editor and reviewers, please use the contact form at http://www.ec-earth.org/ about/contact. The Python scripts to produce the figures of this article are available on Zenodo: https://zenodo.org/record/4291971.

Conflict of interest The authors declare that they have no conflict of interest.

Open Access This article is licensed under a Creative Commons Attribution 4.0 International License, which permits use, sharing, adaptation, distribution and reproduction in any medium or format, as long as you give appropriate credit to the original author(s) and the source, provide a link to the Creative Commons licence, and indicate if changes were made. The images or other third party material in this article are included in the article's Creative Commons licence, unless indicated otherwise in a credit line to the material. If material is not included in the article's Creative Commons licence and your intended use is not permitted by statutory regulation or exceeds the permitted use, you will need to obtain permission directly from the copyright holder. To view a copy of this licence, visit http://creativecommons.org/licenses/by/4.0/.

\section{References}

Alexander MA, Scott JD, Friedland KD, Mills KE, Nye JA, Pershing AJ, Thomas AC (2018) Projected sea surface temperatures over the 21st century: Changes in the mean, variability and extremes for large marine ecosystem regions of Northern Oceans. Elementa Scie Anthropocene 6(9), https://doi.org/10.1525/elementa.191

Arthun M, Eldevik T, Smedsrud LH, Skagseth O, Ingvaldsen RB (2012) Quantifying the influence of Atlantic heat on Barents
Sea ice variability and retreat. J Clim 25:4736-4743. https://doi. org/10.1175/JCLI-D-11-00466.1

Arthun M, Eldevik T, Smedsrud LH (2019) The role of Atlantic heat transport in future Arctic winter sea ice loss. J Clim 32:33273341. https://doi.org/10.1175/JCLI-D-18-0750.1

Auclair G, Tremblay B (2018) The role of ocean heat transport in rapid sea ice declines in the community earth system model Large Ensemble. J Geophys Res 123:8941-8957. https://doi. org/10.1029/2018JC014525

Balsamo G, Beljaars A, Scipal K, Viterbo P, van den Hurk B, Hirschi M, Betts AK (2009) A revised hydrology for the ECMWF model: Verification from field site to terrestrial water storage and impact in the Integrated Forecast System. J Hydrometeorol 10:623-643. https://doi.org/10.1175/2008JHM1068.1

Beszczynska-Möller A, Fahrbach E, Schauer U, Hansen E (2012) Variability in Atlantic water temperature and transport at the entrance to the Arctic Ocean, 1997-2010. ICES J Mar Sci 69(5):852-863. https://doi.org/10.1093/icesjms/fss056

Burgard C, Notz D (2017) Drivers of Arctic Ocean warming in CMIP5 models. Geophys Res Lett 44:4263-4271. https://doi. org/10.1002/2016GL072342

Carmack E, Polyakov I, Padman L, Fer I, Hunke E, Hutchings J, Jackson J, Kelley K, Kwok R, Layton C, Melling H, Perovich D, Persson O, Ruddick B, Timmermans ML, Toole J, Ross T, Vavrus S, Winsor P (2015) Toward quantifying the increasing role of oceanic heat in sea ice loss in the new Arctic. Bull Am Meteorol Soc pp 2079-2105, https://doi.org/10.1175/BAMSD-13-00177.1

Craig A, Valcke S, Coquart L (2017) Development and performance of a new version of the OASIS coupler, OASIS3-MCT3.0. Geosci Model Dev 10:3297-3308

Curry B, Lee CM, Petrie B (2011) Volume, freshwater, and heat fluxes through Davis Strait, 2004-05. J Phys Oceanogr 41:429-436. https://doi.org/10.1175/2010JPO4536.1

Ding Q, Schweiger A, L'Heureux M, Battisti DS, Po-Chedley S, Johnson NC, Blanchard-Wrigglesworth E, Harnos K, Zhang Q, Eastman R, Steig EJ (2017) Influence of high-latitude atmospheric circulation changes on summertime Arctic sea ice. Nat Clim Change 7:289-295. https://doi.org/10.1038/nclimate3241

Docquier D, Grist JP, Roberts MJ, Roberts CD, Semmler T, Ponsoni L, Massonnet F, Sidorenko D, Sein DV, Iovino D, Bellucci A, Fichefet T (2019) Impact of model resolution on Arctic sea ice and North Atlantic Ocean heat transport. Clim Dyn 53:4989-5017. https://doi.org/10.1007/s00382-019-04840-y

Docquier D, Fuentes-Franco R, Koenigk T, Fichefet T (2020) Sea ice - ocean interactions in the Barents Sea modeled at different resolutions. Front Earth Sci 8(172), https://doi.org/10.3389/feart .2020 .00172

Döscher R, et al. (2020) The EC-Earth3 Earth System Model for the Climate Model Intercomparison Project 6. In prep

EC-Earth-Consortium (2019) EC-Earth-Consortium EC-Earth3-Veg model output prepared for CMIP6 CMIP historical. https://doi. org/10.22033/ESGF/CMIP6.4706, Earth System Grid Federation

Goosse H, Kay JE, Armour KC, Bodas-Salcedo A, Chepfer H, Docquier D, Jonko A, Kushner PJ, Lecomte O, Massonnet F, Park HS, Pithan F, Svensson G, Vancoppenolle M (2018) Quantifying climate feedbacks in polar regions. Nat Commun 9(1919) https:// doi.org/10.1038/s41467-018-04173-0

IPCC (2019) Summary for Policymakers. In: IPCC Special Report on the Ocean and Cryosphere in a Changing Climate [H.-O. Pörtner, D.C. Roberts, V. Masson-Delmotte, P. Zhai, M. Tignor, E. Poloczanska, K. Mintenbeck, M. Nicolai, A. Okem, J. Petzold, B. Rama, N. Weyer (eds.)]. Cambridge University Press, Cambridge, United Kingdom and New York, NY, USA

Keen A, Blockley E, Bailey D, Debernard JB, Bushuk M, Delhaye S, Docquier D, Feltham D, Massonnet F, O'Farell S, Ponsoni 
L, Rodriguez JM, Schroeder D, Swart N, Toyoda T, Tsujino H, Vancoppenolle M, Wyser K (2020) An inter-comparison of the mass budget of the arctic sea ice in cmip6 models. Cryosphere Discussions. https://doi.org/10.5194/tc-2019-314

Koenigk T, Brodeau L (2014) Ocean heat transport into the Arctic in the twentieth and twenty-first century in EC-Earth. Clim Dyn 42:3101-3120. https://doi.org/10.1007/s00382-013-1821-x

Kwok R (2018) Arctic sea ice thickness, volume, and multiyear ice coverage: losses and coupled variability (1958-2018). Environ Res Let 13(10), https://doi.org/10.1088/1748-9326/aae3ec

Lavergne T, Sorensen AM, Kern S, Tonboe R, Notz D, Aaboe S, Bell L, Dybkjaer G, Eastwood S, Gabarro C, Heygster G, Killie MA, Kreiner MB, Lavelle J, Saldo R, Sandven S, Pedersen LT (2019) Version 2 of the EUMETSAT OSI SAF and ESA CCI sea-ice concentration climate data records. The Cryosphere 13:49-78. https://doi.org/10.5194/tc-13-49-2019

Lien VS, Schlichtholz P, Skagseth O, Vikebo FB (2017) Winddriven Atlantic Water flow as a direct mode for reduced Barents Sea ice cover. J Clim 30:803-812. https://doi.org/10.1175/ JCLI-D-16-0025.1

Lindsay R, Schweiger A (2015) Arctic sea ice thickness loss determined using subsurface, aircraft, and satellite observations. The Cryosphere 9:269-283. https://doi.org/10.5194/tc-9-269-2015

Liu Z, Alexander M (2007) Atmospheric bridge, oceanic tunnel, and global climatic teleconnections. Rev Geophys 45(2):RG2005. https://doi.org/10.1029/2005RG000172

Li D, Zhang R, Knutson TR (2017) On the discrepancy between observed and CMIP5 multi-model simulated Barents Sea winter sea ice decline. Nat Commun 8(14991), https://doi.org/10.1038/ ncomms 14991

Madec G (2016) NEMO ocean engine. Note du Pôle de modélisation, Institut Pierre-Simon Laplace (IPSL), France, No 27, ISSN No 1288-1619

Mahlstein I, Knutti R (2011) Ocean heat transport as a cause for model uncertainty in projected Arctic warming. J Clim 24:1451-1460. https://doi.org/10.1175/2010JCLI3713.1

Massonnet F, Vancoppenolle M, Goosse H, Docquier D, Fichefet T, Blanchard-Wrigglesworth E (2018) Arctic sea-ice change tied to its mean state through thermodynamic processes. Nat Clim Change 8:599-603. https://doi.org/10.1038/s41558-018-0204-z

Meredith M, Sommerkorn M, Cassotta S, Derksen C, Ekaykin A, Hollowed A, Kofinas G, Mackintosh A, Melbourne-Thomas J, Muelbert MMC, Ottersen G, Pritchard H, Schuur EAG (2019) Polar Regions. In: IPCC Special Report on the Ocean and Cryosphere in a Changing Climate [H.-O. Pörtner, D.C. Roberts, V. MassonDelmotte, P. Zhai, M. Tignor, E. Poloczanska, K. Mintenbeck, M. Nicolai, A. Okem, J. Petzold, B. Rama, N.M. Weyer (eds.)]. Cambridge University Press, Cambridge, United Kingdom and New York, NY, USA

Muilwijk M, Smedsrud LH, Ilicak M, Drange H (2018) Atlantic Water heat transport variability in the 20th century Arctic Ocean from a global ocean model and observations. J Geophys Res 123:8159_ 8179. https://doi.org/10.1029/2018JC014327

Muilwijk M, Ilicak M, Cornish S, Danilov S, Gelderloos R, Gerdes R, Haid V, Haine TWN, Johnson HL, Kostov Y, Kovacs T, Lique C, Marson JM, Myers PG, Scott J, Smedsrud LH, Talandier C, Wang Q (2019) Arctic Ocean response to Greenland Sea wind anomalies in a suite of model simulations. J Geophys Res 124:6286-6322. https://doi.org/10.1029/2019JC015101

Notz D, Marotzke J (2012) Observations reveal external driver for Arctic sea-ice retreat. Geophys Res Lett 39:L08502. https://doi. org/10.1029/2012GL051094

Notz D, Stroeve J (2016) Observed Arctic sea-ice loss directly follows anthropogenic CO2 emission. Science 354(6313):747-750. https ://doi.org/10.1126/science.aag2345
Polyakov IV, Pnyushkov AV, Alkire MB, Ashik IM, Baumann TM, Carmack EC, Goszczko I, Guthrie J, Ivanov VV, Kanzow T, Krishfield R, Kwok R, Sundfjord A, Morison J, Rember R, Yulin A (2017) Greater role for Atlantic inflows on sea-ice loss in the Eurasian Basin of the Arctic Ocean. Science 356(6335):285-291. https://doi.org/10.1126/science.aai8204

Rousset C, Vancoppenolle M, Madec G, Fichefet T, Flavoni S, Barthélemy A, Benshila R, Chanut J, Levy C, Masson S, Vivier F (2015) The Louvain-La-Neuve sea ice model LIM3.6: global and regional capabilities. Geosci Model Dev 8:2991-3005. https://doi. org/10.5194/gmd-8-2991-2015

Ruprich-Robert Y, Msadek R, Castruccio F, Yeager S, Delworth T, Danabasoglu G (2017) Assessing the climate impacts of the observed Atlantic Multidecadal Variability using the GFDL CM2.1 and NCAR CESM1 global coupled models. J Clim 30:2785-2810. https://doi.org/10.1175/JCLI-D-16-0127.1

Sando AB, Gao Y, Langehaug R (2014) Poleward ocean heat transports, sea ice processes, and Arctic sea ice variability in NorESM1-M simulations. J Geophys Res 119:2095-2108. https ://doi.org/10.1002/2013JC009435

Schauer U, Beszczynksa-Möller A (2009) Problems with estimation and interpretation of oceanic heat transport-conceptual remarks for the case of Fram Strait in the Arctic Ocean. Ocean Sci 5:487494. https://doi.org/10.5194/os-5-487-2009

Schweiger A, Lindsay R, Zhang J, Steele M, Stern H, Kwok R (2011) Uncertainty in modeled Arctic sea ice volume. J Geophys Res 116:C00D06. https://doi.org/10.1029/2011JC007084

Schweiger A, Wood KR, Zhang J (2019) Arctic sea ice volume variability over 1901-2010: a model-based reconstruction. J Clim 32:4731-4752. https://doi.org/10.1175/JCLI-D-19-0008.1

Serreze MC, Barrett AP, Crawford AD, Woodgate RA (2019) Monthly variability in Bering Strait oceanic volume and heat transports, links to atmospheric circulation and ocean temperature, and implications for sea ice conditions. J Geophys Res 124(12):9317-9337. https://doi.org/10.1029/2019JC015422

Servonnat J, Mignot J, Guilyardi E, Swingedouw D, Séférian R, Labetoulle S (2015) Reconstructing the subsurface ocean decadal variability using surface nudging in a perfect model framework. Clim Dyn 44:315-338. https://doi.org/10.1007/s00382-014-2184-7

Smedsrud LH, Ingvaldsen R, Nilsen JEO, Skagseth O (2010) Heat in the Barents Sea: transport, storage, and surface fluxes. Ocean Sci 6:219-234. https://doi.org/10.5194/os-6-219-2010

Smeed D, Moat B, Rayner D, Johns W, Baringer M, Volkov D, FrajkaWilliams E (2019) Atlantic meridional overturning circulation observed by the RAPID-MOCHA-WBTS (RAPID-Meridional Overturning Circulation and Heatflux Array-Western Boundary Time Series) array at $26 \mathrm{~N}$ from 2004 to 2018. https://doi. org/10.5285/8cd7e7bb-9a20-05d8-e053-6c86abc012c2, http:// www.rapid.ac.uk/rapidmoc/rapid_data/datadl.php

Smith B, Warlind D, Arneth A, Hickler T, Leadley P, Siltberg J, Zaehle $\mathrm{S}$ (2014) Implications of incorporating $\mathrm{N}$ cycling and $\mathrm{N}$ limitations on primary production in an individual-based dynamic vegetation model. Biogeosciences 11:2027-2054. https://doi. org/10.5194/bg-11-2027-2014

Swart NC, Fyfe JC, Hawkins E, Kay JE, Jahn A (2015) Influence of internal variability on arctic sea-ice trends. Nat Clim Change 5:86-89. https://doi.org/10.1038/nclimate2483

Tsamados M, Feltham D, Petty A, Schroeder D, Flocco D (2015) Processes controlling surface, bottom and lateral melt of Arctic sea ice in a state of the art sea ice model. Philosophical Trans Ro Soc A 373(2052), https://doi.org/10.1098/rsta.2014.0167

van der Linden EC, LeBars D, Bintanja R, Hazeleger W (2019) Oceanic heat transport into the Arctic under high and low $\mathrm{CO} 2$ forcing. Clim Dyn 53:4763-4780. https://doi.org/10.1007/s0038 2-019-04824-y 
Walsh JE, Hetter F, Stewart JS, Chapman WL (2017) A database for depicting Arctic sea ice variations back to 1850. Geograph Rev 107(1):89-107. https://doi.org/10.1111/j.1931-0846.2016.12195.x

Woodgate RA (2018) Increases in the Pacific inflow to the Arctic from 1990 to 2015, and insights into seasonal trends and driving mechanisms from year-round Bering Strait mooring data. Progress Oceanogr 160:124-154. https://doi.org/10.1016/j.pocea n.2017.12.007
Zhang J, Rothrock DA (2003) Modeling global sea ice with a thickness and enthalpy distribution model in generalized curvilinear coordinates. Mon Weather Rev 131:845-861

Publisher's Note Springer Nature remains neutral with regard to jurisdictional claims in published maps and institutional affiliations. 